\title{
Thermodynamics of the Fe-N and Fe-N-C Systems: The Fe-N and Fe-N-C Phase Diagrams Revisited
}

\author{
HOLGER GÖHRING, OLGA FABRICHNAYA, ANDREAS LEINEWEBER, \\ and ERIC JAN MITTEMEIJER
}

\begin{abstract}
Several thermodynamic descriptions of the Fe-N and $\mathrm{Fe}-\mathrm{N}-\mathrm{C}$ systems were proposed before now. The results of these descriptions significantly deviate from more recently obtained experimental data. The present work provides a revised thermodynamic description of these systems. The new description for the Fe-N system agrees distinctly better with the experimental data especially for the equilibrium of $\gamma^{\prime}-\mathrm{Fe}_{4} \mathrm{~N}_{1-x}$ and $\varepsilon-\mathrm{Fe}_{3} \mathrm{~N}_{1+z}$. The new thermodynamic description for the Fe-N-C system considering the Fe-rich part of the system with less than 33 at. pct $\mathrm{N}$ and less than 25 at. pct $\mathrm{C}$ excellently agrees with the new experimental data for both the temperatures of the invariant reactions and the phase boundaries. This in particular concerns the temperature range of typical technical nitriding and nitrocarburizing treatments [723 K to $923 \mathrm{~K},\left(450{ }^{\circ} \mathrm{C}\right.$ to $\left.650{ }^{\circ} \mathrm{C}\right)$ ], within which three invariant reactions occur in the ternary system.
\end{abstract}

DOI: $10.1007 / \mathrm{s} 11661-016-3731-0$

(C) The Author(s) 2016. This article is published with open access at Springerlink.com

\section{INTRODUCTION}

THE Fe-C, Fe-N and Fe-N-C systems are highly relevant for Fe-based components, in particular if these are subjected to technically applied nitriding and nitrocarburizing treatments. ${ }^{[1]}$ The $\mathrm{Fe}-\mathrm{N}-\mathrm{C}$ equilibrium phases considered in the present work have been listed in Table I, as assembled from References 2 and 3.

The binary $\mathrm{Fe}-\mathrm{C}$ system is the basis of all technically applied steels. ${ }^{[4]}$ The stable phases in the binary Fe-C system $^{[5]}$ are the terminal interstitial solid solution phases $\alpha$ (ferrite) and $\gamma$ (austenite), the liquid solution phase and graphite. However, due to kinetically obstructed precipitation of graphite, at carbon contents of up to 25 at. pct, the iron carbide cementite, $\theta-\mathrm{Fe}_{3} \mathrm{C}_{1-\delta}$, occurs in metastable equilibria. Recently, the non-stoichiometry of $\theta$ in equilibrium with $\alpha$ and $\gamma$ with positive values of $\delta$, has been quantified. ${ }^{[6]}$ On this basis, a new thermodynamic description for the cementite phase has been presented, ${ }^{[7]}$ which, in contrast to the previous descriptions, ${ }^{[8-11]}$ recognizes and well describes its non-stoichiometric character.

HOLGER GÖHRING, Ph.D. Student, is with the Max Planck Institute for Intelligent Systems (formerly Max Planck Institute for Metals Research), Heisenbergstraße 3, 70569 Stuttgart, Germany. Contact e-mail: h.goehring@is.mpg.de OLGA FABRICHNAYA, Research Scientist, is with the Institute of Materials Science, TU Bergakademie Freiberg, Gustav-Zeuner-Str. 5, 09599 Freiberg, Germany. ANDREAS LEINEWEBER, formerly Research Scientist with the Max Planck Institute for Intelligent Systems (formerly Max Planck Institute for Metals Research), is now Professor with the Institute of Materials Science, TU Bergakademie Freiberg. ERIC JAN MITTEMEIJER, Director, is with the Max Planck Institute for Intelligent Systems (formerly Max Planck Institute for Metals Research), and also Professor with the Institute for Materials Science, University of Stuttgart, Stuttgart, Germany.

Manuscript submitted March 16, 2016.

Article published online October 3, 2016
The constitution of compound layers developing upon nitriding of $\mathrm{Fe}$ can be predicted by the $\mathrm{Fe}-\mathrm{N}$ phase diagram, ${ }^{[12]}$ assuming local equilibrium in the solid state, featuring the interstital solid solution phases $\alpha$ (ferrite) and $\gamma$ (austenite) and the iron nitride phases $\gamma^{\prime}-\mathrm{Fe}_{4} \mathrm{~N}_{1-x}$ and $\varepsilon-\mathrm{Fe}_{3} \mathrm{~N}_{1+z}$. In order to identify such local equilibria, the Fe-N system to be considered, as discussed above for the $\mathrm{Fe}-\mathrm{C}$ system, represents metastable equilibrium states, corresponding to suppression of the formation of $\mathrm{N}_{2}$ gas. In genuine equilibria, iron-nitride phases such as $\gamma^{\prime}$ and $\varepsilon$ do not occur. Metastable equilibria in the Fe- $\mathrm{N}$ system can be investigated by gas-nitriding experiments using $\mathrm{NH}_{3} / \mathrm{H}_{2}$ atmospheres, defining the chemical potential of $\mathrm{N}$ in the gas phase. ${ }^{[1]}$ For data obtained from such gas-nitrided specimens, furthermore the establishment of a steady state instead of a local equilibrium at the surface of the specimens, i.e., equality of the rate of $\mathrm{N}$ dissolution and recombination instead of equality of the chemical potential of $\mathrm{N}$ in the gas phase and in the solid, has to be considered: the $\mathrm{N}$ concentration will then be lower than that corresponding to local metastable equilibrium with the gas atmosphere. ${ }^{[1,13]}$ The effect becomes significant above approximately $853 \mathrm{~K}\left(580{ }^{\circ} \mathrm{C}\right)$ for nitrided ferrite $(\alpha)^{[13]}$ and is more pronounced for increasing nitrogen content in the solid matrix and thus becomes significant at the surface of $\varepsilon$-iron nitride (containing $>30$ at. pct $\mathrm{N})$ already at $723 \mathrm{~K}\left(450^{\circ} \mathrm{C}\right) .{ }^{[14]}$

Until today, the experimental data set for the Fe-N system as compiled in Reference 12 is the most complete experimental description of the system and largely provides the basis for the optimisation of thermodynamic parameters in the present work. Recently, some additional data on the constitution of the system have been published ${ }^{[13,15]}$ that are also considered in the present work. CALPHAD-type thermodynamic 
Table I. Phases Considered in the Present Work, Their Crystal Structure, and Formula Units of Their Sublattice Models

\begin{tabular}{|c|c|c|c|}
\hline Phase & Space Group & Structure & Formula Unit \\
\hline Ferrite, $\alpha-\mathrm{Fe}[\mathrm{N}, \mathrm{C}]$ & $\operatorname{Im} \overline{3} m$ & bcc Fe lattice with $\mathrm{N}$ and $\mathrm{C}$ on octahedral sites ( 3 per Fe atom) & $\mathrm{Fe}(\mathrm{C}, \mathrm{N}, \mathrm{Va})_{3}$ \\
\hline Austenite, $\gamma-\mathrm{Fe}[\mathrm{N}, \mathrm{C}]$ & $F m \overline{3} m$ & fcc Fe with $\mathrm{N}$ and $\mathrm{C}$ on octahedral sites & $\mathrm{Fe}(\mathrm{C}, \mathrm{N}, \mathrm{Va})$ \\
\hline$\gamma^{\prime}-\mathrm{Fe}_{4} \mathrm{~N}_{1-z}$ & $\operatorname{Pm} \overline{3} m$ & $\begin{array}{l}\text { fcc-type Fe lattice, } \mathrm{N} \text { and } \mathrm{C} \text { ordered on one octahedral site per unit } \\
\text { cell }\end{array}$ & $\mathrm{Fe}_{4}(\mathrm{C}, \mathrm{N}, \mathrm{Va})$ \\
\hline$\varepsilon-\mathrm{Fe}_{3}(\mathrm{~N}, \mathrm{C})_{1+x}$ & $P 6_{3} 22, P 312$ & $\begin{array}{l}\text { hcp-type Fe lattice, } \mathrm{N} \text { and } \mathrm{C} \text { on every second octahedral site with } \\
\text { different types of order }{ }^{a}\end{array}$ & $\mathrm{Fe}(\mathrm{C}, \mathrm{N}, \mathrm{Va})_{1 / 2}$ \\
\hline$\theta-\mathrm{Fe}_{3} \mathrm{C}_{1-\delta}$ & Pnma & distorted hcp-type Fe lattice, $\mathrm{C}$ in trigonal prisms & $\mathrm{Fe}_{3}(\mathrm{C}, \mathrm{Va})$ \\
\hline
\end{tabular}

${ }^{\mathrm{a}}$ The chosen formula unit of the sublattice model does not assume a specific state of order. It is, however, noted that octahedral sites adjacent in the $c$ direction cannot be occupied simultaneously. ${ }^{[14,30]}$

descriptions for the Fe-N system have been published in References 8 and 16 through 24. In general, for the intermediate phases $\gamma^{\prime}$ and $\varepsilon$, these descriptions only consider random mixing of nitrogen on an interstitial sublattice, and thus excess Gibbs energy parameters have to be introduced to describe the deviation of the real system from such ideal behavior. Theoretical approaches to describe the thermodynamics of nitrogen ordering and disordering have been presented for $\gamma^{\prime[25-29]}$ and $\varepsilon .^{[14,27,30-33]}$

Upon nitrocarburizing of $\mathrm{Fe}$, a simultaneous uptake of $\mathrm{N}$ and $\mathrm{C}$ into the substrate occurs. ${ }^{[1]}$ Upon only nitriding of technical steel, interactions of $\mathrm{N}$ and $\mathrm{C}$ have to be considered as well, due to (initial) $\mathrm{C}$ present in the substrate. A first systematic study of the ternary Fe-N-C system has been provided in Reference 34. Subsequent work has been presented in References 35 and 36. All these early works have in common that they do not include the possibility of an $\alpha+\varepsilon$ equilibrium. Furthermore, the appearance of $\gamma$ is concluded to occur at a temperature as low as $838 \mathrm{~K}\left(565^{\circ} \mathrm{C}\right)$ in Reference 36 , in flagrant contrast with later experimental data. ${ }^{[15]}$

In contrast to these early experimental works, ${ }^{[34-36]}$ the observation of microstructures forming upon nitriding of $\mathrm{Fe}-\mathrm{C}$ alloys and $\mathrm{C}$-containing steels and upon nitrocarburizing pure $\mathrm{Fe}, \mathrm{Fe}-\mathrm{C}$ alloys, and $\mathrm{C}$-containing steels, which do contain interfaces between $\alpha$ and $\varepsilon^{[37-47]}$ makes it very likely that equilibrium between $\alpha$ and $\varepsilon$ does occur, albeit in a narrow temperature range. Later works ${ }^{[15,48-53]}$ confirmed the occurrence of such microstructures. Except for an early work, ${ }^{[54]}$ the $\alpha+\varepsilon$ equilibrium is taken into account in all thermodynamic descriptions of the $\mathrm{Fe}-\mathrm{N}-\mathrm{C}$ system in the literature. $^{[20,22,24,55-57]}$ However, systematic experimental work to investigate the occurrence of the $\alpha+\varepsilon$ equilibrium $^{[48,53]}$ showed that the experimentally determined temperatures of the invariant reactions leading to the appearance of this equilibrium deviate from the temperatures as predicted using each of the thermodynamic descriptions from the literature. ${ }^{[20,22,24,55-57]}$ Additionally, a recent experimental study of the constitution in the system $\mathrm{Fe}-\mathrm{N}-\mathrm{C}$ for the temperature range above $853 \mathrm{~K}\left(580{ }^{\circ} \mathrm{C}\right),{ }^{[15]}$ investigating both the phase boundaries and the temperatures of the invariant reactions involving $\gamma$, showed bad agreement with again each of the thermodynamic descriptions from the literature. ${ }^{[20,22,24,55-57]}$ Finally, analysis of the thermodynamic factors derived from $\mathrm{N}$ and $\mathrm{C}$ diffusivities in ternary $\varepsilon$ at $823 \mathrm{~K}\left(550{ }^{\circ} \mathrm{C}\right)^{[58]}$ and $853 \mathrm{~K}\left(580{ }^{\circ} \mathrm{C}\right)^{[51]}$ showed agreement with the thermodynamic descriptions of $\varepsilon$ given in References 20 and 24 and disagreement with the one from Reference 22 .

In the present work, new thermodynamic assessments of the $\mathrm{Fe}-\mathrm{N}$ and $\mathrm{Fe}-\mathrm{N}-\mathrm{C}$ systems are presented, using the newly obtained data in the optimization process in order to eliminate the discrepancies associated with the previous thermodynamic descriptions. As a result, for the first time a description of the Fe-N-C system was obtained that is compatible with all experimental data and thus is suitable for nitriding and nitrocarburizing applications. Furthermore, significant improvements in the description of the binary Fe-N system were achieved: (i) a simpler model for the $\gamma^{\prime}$ phase, accounting for its homogeneity range but using fewer parameters than the thermodynamic description from Reference 22 and (ii) an improved description of the $\gamma^{\prime}+\varepsilon$ equilibrium at high $\mathrm{N}$ contents.

\section{THERMODYNAMIC MODEL OF THE FE-N AND FE-N-C SOLID SOLUTION PHASES}

The Fe-N and Fe-N-C solid solution phases can be described by the compound-energy formalism, ${ }^{[59,60]}$ also called Hillert-Staffansson approach. ${ }^{[61]}$ In the following, only an Fe-N-C solid solution phase is considered; a similar treatment is used for an Fe-N (and an Fe-C) solid solution phase.

The interstitial solution of $\mathrm{N}$ and $\mathrm{C}$ in a phase $\varphi$ is considered as a mixture of the hypothetical compounds $\mathrm{Fe}_{a} \mathrm{C}_{c}, \mathrm{Fe}_{a} \mathrm{~N}_{c}$ and $\mathrm{Fe}_{a} \mathrm{Va}_{c}$ (with $\mathrm{Va}$ standing for vacancies) with $a$ and $c$ being stoichiometric indices determined by the crystal structure of the phase $\varphi$. The total Gibbs energy of the phase $\varphi$ with the formula $\mathrm{Fe}_{a}(\mathrm{C}, \mathrm{N}, \mathrm{Va})_{c}$ per formula unit reads

$$
\begin{aligned}
G_{\mathrm{m}}^{\varphi}= & y_{\mathrm{C}}^{\varphi}{ }^{\circ} G_{\mathrm{Fe}: \mathrm{C}}^{\varphi}+y_{\mathrm{N}}^{\varphi}{ }^{\circ} G_{\mathrm{Fe}: \mathrm{N}}^{\varphi}+y_{\mathrm{Va}}^{\varphi}{ }^{\circ} G_{\mathrm{Fe}: \mathrm{Va}}^{\varphi} \\
& +c R T\left(y_{\mathrm{C}}^{\varphi} \ln y_{\mathrm{C}}^{\varphi}+y_{\mathrm{N}}^{\varphi} \ln y_{\mathrm{N}}^{\varphi}+y_{\mathrm{Va}}^{\varphi} \ln y_{\mathrm{Va}}^{\varphi}\right)+G^{\varphi, \mathrm{ex}} \\
& +G^{\varphi, \mathrm{mag}},
\end{aligned}
$$

with $y_{\mathrm{C}}^{\varphi}, y_{\mathrm{N}}^{\varphi}$ and $y_{\mathrm{Va}}^{\varphi}$ representing the fractions of sublattice occupancies of $\mathrm{C}, \mathrm{N}$, and $\mathrm{Va}$, respectively, recognizing that the first sublattice is always completely occupied by $\mathrm{Fe}$, i.e., $y_{\mathrm{Fe}}^{\varphi}=1$, the Gibbs energies ${ }^{\circ} G_{\mathrm{Fe}: \mathrm{C}}^{\varphi}$, 
${ }^{\circ} G_{\mathrm{Fe}: \mathrm{N}}^{\varphi}$, and ${ }^{\circ} G_{\mathrm{Fe}: \mathrm{Va}}^{\varphi}$ of the hypothetical non-magnetic compounds $\mathrm{Fe}_{a} \mathrm{C}_{c}, \mathrm{Fe}_{a} \mathrm{~N}_{c}$, and $\mathrm{Fe}_{a} \mathrm{Va}_{c}$, the so-called end-members, with $\mathrm{Fe}: \mathrm{C}, \mathrm{Fe}: \mathrm{N}$, and $\mathrm{Fe}: \mathrm{Va}$ denoting that the second sublattice is fully occupied by $\mathrm{C}, \mathrm{N}$, and Va, respectively, the excess Gibbs energy $G^{\varphi, \text { ex }}$ and the magnetic contribution $G^{\varphi, m a g}$.

The Gibbs energy of the end members is usually described as a temperature series according to e.g., for $\mathrm{Fe}_{a} \mathrm{~N}_{c}$ :

$$
\begin{aligned}
& { }^{\circ} G_{\mathrm{Fe}: \mathrm{N}}^{\varphi}-a^{\circ} G_{\mathrm{Fe}}^{\mathrm{ref}}-c^{\circ} G_{\mathrm{N}}^{\mathrm{ref}}=a+b T \\
& \quad+c T \ln T+d_{1} T^{2}+d_{2} T^{-1}+d_{3} T^{3} .
\end{aligned}
$$

with the reference Gibbs energies for $\mathrm{Fe}$ and $\mathrm{N},{ }^{\circ} G_{\mathrm{Fe}}^{\mathrm{ref}}$ and ${ }^{\circ} G_{\mathrm{N}}^{\mathrm{ref}}$ and the model parameters $a, b, c, d_{i}$. The reference state is usually the SER state, i.e., the enthalpy of the elements in their most stable state at $298 \mathrm{~K}$ $\left(25^{\circ} \mathrm{C}\right)$ and $1 \times 10^{5} \mathrm{~Pa}$.

The excess Gibbs energy is described as

$$
\begin{aligned}
G^{\varphi, \mathrm{ex}}= & y_{\mathrm{C}}^{\varphi} y_{\mathrm{N}}^{\varphi} L_{\mathrm{Fe}: \mathrm{C}, \mathrm{N}}^{\varphi}+y_{\mathrm{C}}^{\varphi} y_{\mathrm{Va}}^{\varphi} L_{\mathrm{Fe}: \mathrm{C}, \mathrm{Va}}^{\varphi} \\
& +y_{\mathrm{N}}^{\varphi} y_{\mathrm{Va}}^{\varphi} L_{\mathrm{Fe}: \mathrm{N}, \mathrm{Va}}^{\varphi},
\end{aligned}
$$

only considering binary interaction parameters $L_{\mathrm{Fe}: \mathrm{C}, \mathrm{N}}^{\varphi}$, $L_{\mathrm{Fe}: \mathrm{C}, \mathrm{Va}}^{\varphi}$ and $L_{\mathrm{Fe}: \mathrm{N}, \mathrm{Va}}^{\varphi}$, with their composition dependence described by a Redlich-Kister series ${ }^{[62]}$.

$$
L_{\mathrm{Fe}: \mathrm{C}, \mathrm{N}}^{\varphi}=\sum_{k}{ }^{k} L_{\mathrm{Fe}: \mathrm{C}, \mathrm{N}}^{\varphi}\left(y_{\mathrm{C}}^{\varphi}-y_{\mathrm{N}}^{\varphi}\right)^{k},
$$

and analogously for $L_{\mathrm{Fe}: \mathrm{C}, \mathrm{Va}}$ and $L_{\mathrm{Fe}: \mathrm{N}, \mathrm{Va}}^{\varphi}$. In the present work, interaction parameters of zeroth and first order are used (i.e., $k=0,1)$. These treatments correspond to a regular and a sub-regular solution model, respectively, whereas $G^{\varphi, \text { ex }}=0$ corresponds to an ideal solution model. ${ }^{[63]}$ For the magnetic contribution $G^{\varphi, m a g}$ of the $\alpha, \gamma$ and $\theta$ phases, the Inden model ${ }^{[64,65]}$ is used, taking the magnetic moment $\beta^{\varphi}$ and the Curie (for $\alpha$ and $\theta$ ) or Néel (for $\gamma$ ) temperature $T_{\text {Curie, }}^{\varphi}$ or $T_{\text {Néel, }}^{\varphi}$ as (potentially concentration-dependent) model parameters, as described in detail in Reference 60. For $\gamma^{\prime}$ and $\varepsilon$ no separate magnetic contribution is modeled (see Section IV).

\section{EMPLOYED DATA FOR THE THERMODYNAMIC PARAMETER OPTIMIZATION}

\section{A. Binary $\mathrm{Fe}-\mathrm{N}$ Data}

For the binary system $\mathrm{Fe}-\mathrm{N}$, the data as assembled in Reference $12^{[25,35,36,66-85]}$ was chosen according to the recommendations given there. The binary thermodynamic descriptions of the $\alpha$ and $\gamma$ phase were taken from Reference 22; for the choice of parameters to be optimized, see Section IV. Thus, only equilibrium data including the phases $\gamma^{\prime}$ or $\varepsilon$ have been used, in particular the data for the $\alpha+\gamma^{\prime}, \gamma+\gamma^{\prime}, \gamma+\varepsilon$, and $\gamma^{\prime}+\varepsilon$ two-phase equilibria. The available data are compositions and activities at the phase boundaries. If instead of activities, the nitriding potential, a (technical) process parameter ${ }^{[1]}$ was given, the activities were calculated using the Gibbs-energy equations for various gas species given in Reference 86. Newer data for the $\gamma \rightleftarrows \alpha+\gamma^{\prime}$ invariant equilibrium and the $\alpha+\gamma^{\prime}$ two-phase equilibrium $^{[13,87,88]}$ and the $\gamma+\gamma^{\prime}$ and $\gamma+\varepsilon$ equilibria ${ }^{[15,87]}$ were also included. As an additional information, the activity curves for $\gamma^{\prime}$ from References 25 and 82 and for $\varepsilon$ in References 17 and 89 were used. However, these so-called absorption isotherms obtained from gaseous nitriding of $\mathrm{Fe}$ specimens are affected by the establishment of steady states instead of true metastable equilibrium at the surface of the specimen at higher temperatures and $\mathrm{N}$ contents,${ }^{[1,13,14]}$ making it impossible to use all data above $823 \mathrm{~K}\left(550^{\circ} \mathrm{C}\right)$. Already at lower temperatures, but high $\mathrm{N}$ contents ( $>30$ at. pct), a steady state instead of an equilibrium prevails at the surface. Therefore, the affected data have not been used during the optimization. Furthermore, during the optimization process, agreement of the model with the activity data has been considered less important than agreement with the information on solid-solid equilibria.

Based on this experimental information, the parameters ${ }^{\circ} G_{\mathrm{Fe}: \mathrm{N}}^{\gamma^{\prime}}$ and ${ }^{\circ} G_{\mathrm{Fe}: \mathrm{Va}}^{\gamma^{\prime}}$ of $\gamma^{\prime}$ and the parameters ${ }^{0} L_{\mathrm{Fe}: \mathrm{N}, \mathrm{Va}}^{\varepsilon}$ and ${ }^{1} L_{\mathrm{Fe}: \mathrm{N}, \mathrm{Va}}^{\varepsilon}$ of $\varepsilon$ were optimized.

\section{B. Ternary $\mathrm{Fe}-\mathrm{N}-\mathrm{C}$ Data}

For the optimization process of the model parameters for the ternary $\mathrm{Fe}-\mathrm{N}-\mathrm{C}$ system, primarily recently published data was used. During the optimization, care was taken that the resulting invariant temperatures comply with the ranges as determined experimentally in References 15 and 53. The second source of data was the location of the phase boundaries at $853 \mathrm{~K}$ and $893 \mathrm{~K}$ $\left(580{ }^{\circ} \mathrm{C}\right.$ and $\left.620^{\circ} \mathrm{C}\right)$ as determined experimentally in Reference 15. The experimental information that in the considered $\mathrm{C}$ and $\mathrm{N}$ content ranges the off-diagonal components of the thermodynamic factor of $\varepsilon$ are positive $\mathrm{e}^{[51,58]}$ was used as a constraint for the model of the $\varepsilon$ phase. Additionally, the $\mathrm{N}$-solubility data in C-containing $\gamma$ from Reference 90 was used.

For the $\mathrm{C}$ content of $\gamma^{\prime}$, no reliable equilibrium data is available. EPMA investigations on specimens produced for the investigations in References 51 through 53 and 58 showed $\mathrm{C}$ contents in $\gamma^{\prime}$ which were always below 1 at. pct. Therefore, during the optimization care was taken that this level of $\mathrm{C}$ content was not exceeded considerably. In $\theta$ only trace amounts of $\mathrm{N}$ have been found at temperatures $\leq 1073 \mathrm{~K}\left(800{ }^{\circ} \mathrm{C}\right) .{ }^{[91]}$ At lower temperatures, $\theta$ layers can be produced on Fe substrates by heat treatment in an atmosphere containing $\mathrm{CO}$, $\mathrm{NH}_{3}$, and $\mathrm{H}_{2} \cdot{ }^{\left[{ }^{[2]}\right]}$ During the treatment, the substrate is gradually saturated with $\mathrm{N}$ that has diffused through $\theta,{ }^{[93]}$ eventually leading to formation of an $\varepsilon$ layer underneath the $\theta$ layer. ${ }^{[50]} \theta$ produced under these 
conditions has been investigated by atom probe tomography, ${ }^{[94]}$ revealing, nevertheless, a maximum total impurity content of only 0.01 at. pct, also including $\mathrm{N}$. This supports the above experimental results of Reference 91 and is in contrast with the prediction of $\mathrm{N}$ contents of $>1$ at. pct resulting from the thermodynamic description of Reference 22.

On the basis of these ternary experimental data, the binary parameters ${ }^{\circ} G_{\mathrm{Fe}: \mathrm{C}}^{\gamma^{\prime}}$ of $\gamma^{\prime}$ and ${ }^{0} L_{\mathrm{Fe}: \mathrm{C}, \mathrm{Va}}^{\varepsilon}$ and ${ }^{1} L_{\mathrm{Fe} \text { C,Va }}^{\varepsilon}$ of $\varepsilon$, which are only relevant for the ternary system, and the ternary parameters ${ }^{0} L_{\mathrm{Fe}: \mathrm{C}, \mathrm{N}}^{\gamma}$ of $\gamma$ and ${ }^{0} L_{\mathrm{Fe}: \mathrm{C}, \mathrm{N}}^{\varepsilon}$ and ${ }^{1} L_{\mathrm{Fe}: \mathrm{C}, \mathrm{N}}^{\varepsilon}$ of $\varepsilon$ were optimized.

\section{APPLIED MODELS; OPTIMIZATION PROCESS}

The descriptions for the Gibbs energy of the pure elements were taken from Reference 95. The formula units of the sublattice models applied in the present work for each phase have been listed in Table I. A thermodynamic database file is supplied as supplementary data. The values for the parameters of the thermodynamic description for the $\alpha$ phase were taken from Reference 22. For the $\gamma$ phase, only the parameter ${ }^{0} L_{\mathrm{Fe}: \mathrm{C}, \mathrm{N}}^{\gamma}$ was included in the optimization (see end of Section III-B). The values of the binary parameters of $\gamma$ were taken from References 9 and 22.

The thermodynamic parameters of $\gamma^{\prime}$ were completely reassessed (see end of Sections III-A and III-B). In the model for $\gamma^{\prime}$ from Reference 22, ${ }^{\circ} G_{\mathrm{Fe}: \mathrm{Va}}^{\gamma^{\prime}}$ had been set equal to $4^{\circ} G_{\mathrm{Fe}: \mathrm{Va}}^{\gamma}$. In order to correctly model the thermodynamics of $\gamma^{\prime}$, then the interaction parameters ${ }^{0} L_{\mathrm{Fe}: \mathrm{N}, \mathrm{Va}}^{\gamma^{\prime}}$ and ${ }^{1} L_{\mathrm{Fe}: \mathrm{N}, \mathrm{Va}}^{\gamma^{\prime}}$ (both $T$-dependent) had to be introduced in Reference 22. In the present work, ${ }^{\circ} G_{\mathrm{Fe}: \mathrm{Va}}^{\gamma^{\prime}}$ was used as an optimization variable, eliminating the need for any interaction parameters for $\gamma^{\prime}$ and thus reducing the number of parameters as compared to the model of Reference 22. Because of the lack of accurate data for the $\mathrm{C}$ solubility in $\gamma^{\prime}$, the parameter ${ }^{\circ} G_{\mathrm{Fe}: \mathrm{C}}^{\gamma^{\prime}}$ was fixed to a value giving a reasonable homogeneity range of $\gamma^{\prime}$ in the ternary Fe-N-C system. The $\gamma^{\prime}$ phase shows ferromagnetic ordering with a somewhat concentration-dependent Curie temperature around $763 \mathrm{~K}\left(490{ }^{\circ} \mathrm{C}\right) .{ }^{[12]}$ As there is no heat-capacity data available, which would allow introducing the magnetic moment as a fitting parameter, no magnetic model is used*.

The thermodynamic description for the $\theta$ phase was taken directly from Reference 7 . No N solubility had to be modeled as explained in Section III-B.

For the $\varepsilon$ phase, the sublattice model of $\mathrm{Fe}(\mathrm{C}, \mathrm{N}, \mathrm{Va})_{1 / 2}$ as used in References 22 and 55 through 57 was also applied in the present work. The $\varepsilon$ phase shows magnetic ordering with a Curie temperature strongly varying with, at least, the $\mathrm{N}$ content between $10 \mathrm{~K}$ and $550 \mathrm{~K}\left(-260{ }^{\circ} \mathrm{C}\right.$ and $\left.280{ }^{\circ} \mathrm{C}\right) .{ }^{[12]}$ As for the $\gamma^{\prime}$ phase, the lack of heat-capacity data prevents fitting for the magnetic moment, so no magnetic contribution was modeled*. The value of the parameter ${ }^{\circ} G_{\mathrm{Fe}: \mathrm{N}}^{\varepsilon}$ was

* It was shown in an earlier work providing a new thermodynamic description for $\theta^{[7]}$ that the magnetic moments obtained from fitting, specifically of $c_{p}$ curves, are far from experimentally obtained values. Therefore, it was avoided to use such values for the thermodynamic descriptions of $\gamma^{\prime}$ and $\varepsilon$ in the present work.

taken from Reference 22 as during re-optimization attempts on the basis of the available equilibrium data, the $\varepsilon$ phase became unreasonably stable at high temperature. It was also attempted to include the parameter ${ }^{\circ} G_{\mathrm{Fe}: \mathrm{C}}^{\varepsilon}$ in the optimization. This led to the unreasonable appearance of the $\varepsilon$ phase in the binary $\mathrm{Fe}-\mathrm{C}$ system instead of $\theta$ for a large temperature range. Thus, it was decided to keep the value from Reference 96 as also used in Reference 22. The optimization process revealed that several binary interaction parameters of zeroth and first order (sub-regular solution model) were necessary in order to obtain an acceptable description of the $\varepsilon$ phase (see also the discussion in Sections I and especially V-D). The introduction of ternary interaction parameters was not necessary.

The resulting model parameters as determined in this work and as taken from the literature are presented in Table II. If desired, the model for the Fe-N-C liquid phase from Reference 56 can be included.

\section{DISCUSSION}

\section{A. The Binary $\mathrm{Fe}-\mathrm{N}$ Phase Diagram}

The temperatures and the compositions of the phases at the invariant equilibria in the $\mathrm{Fe}-\mathrm{N}$ system, as predicted by the thermodynamic description resulting from the present work, can be compared with the experimental data from References 12, 13, and 15 and the previous predictions from References 22 and 24 in Table III. The agreement of these features of the Fe-N phase diagram with the experimental data is comparably good for the new and old ${ }^{[22,24]}$ thermodynamic descriptions.

The $\mathrm{Fe}-\mathrm{N}$ phase diagram as calculated using the model parameters from the present work is shown in Figure 1. Various enlarged sections of the phase diagram are shown in Figure 2 to allow a more detailed comparison with both the experimental $\operatorname{data}^{[13,15,25,35,36,66,67,70-76,78-82,84,87,88]}$ and the previous predictions from References 22 and 24 .

The homogeneity range of $\alpha$ agrees well with the experimental data and with the homogeneity range resulting from the thermodynamic description of Reference 22 (see Figure 2(a)). The newer experimental data from Reference 13 are better described by the thermodynamic description from Reference 24. This description, however, shows an $\alpha+\varepsilon$ equilibrium below approximately $580 \mathrm{~K}\left(310^{\circ} \mathrm{C}\right)$, a temperature at which the $\alpha+\gamma^{\prime}$ equilibrium is observed experimentally (see 
Table II. Thermodynamic Model Parameters for the Solid Solution Phases as Determined in the Present Work and as Taken from the Cited Literature to be Used with the Unary Gibbs-Energy Functions from Ref. [95]

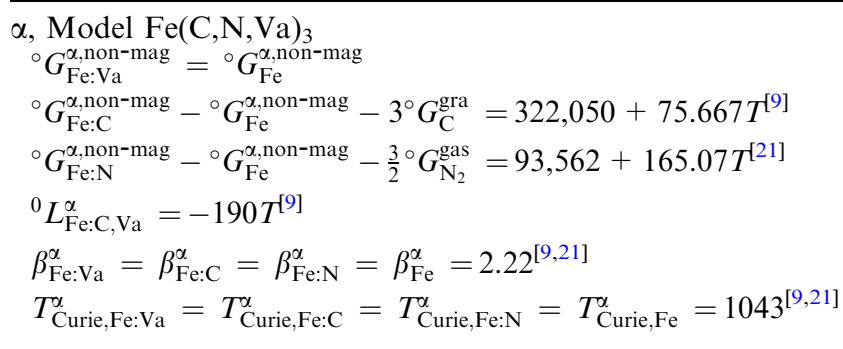

$\gamma$, model $\mathrm{Fe}(\mathrm{C}, \mathrm{N}, \mathrm{Va})$

$$
\begin{aligned}
& { }^{\circ} G_{\mathrm{Fe}: \mathrm{Va}}^{\gamma, \text { non-mag }}={ }^{\circ} G_{\mathrm{Fe}}^{\gamma, \text { non-mag }} \\
& { }^{\circ} G_{\mathrm{Fe} \mathrm{C}}^{\gamma, \text { non-mag }}-{ }^{\circ} G_{\mathrm{Fe}}^{\gamma, \text { non-mag }}-{ }^{\circ} G_{\mathrm{C}}^{\text {gra }}=77,207-15.877 T^{[9]} \\
& { }^{\circ} G_{\mathrm{Fe}: \mathrm{N}}^{\gamma, \text { nonag }}-{ }^{\circ} G_{\mathrm{Fe}}^{\alpha, \text { non-mag }}-\frac{1}{2}{ }^{\circ} G_{\mathrm{N}_{2}}^{\text {gas }}=-20,277+245.3931 T-21.2984 T \ln T^{[22]} \\
& { }^{0} L_{\mathrm{Fe}: \mathrm{C}, \mathrm{Va}}^{\gamma}=-34,671^{[9]} \\
& { }^{0} L_{\mathrm{Fe}: \mathrm{N}, \mathrm{Va}}^{\gamma}=-26,150^{[16]} \\
& { }^{0} L_{\mathrm{Fe}: \mathrm{C}, \mathrm{N}}^{\gamma}=8218 \\
& \beta_{\mathrm{Fe}: \mathrm{Va}}^{\gamma}=\beta_{\mathrm{Fe}: \mathrm{C}}^{\gamma}=\beta_{\mathrm{Fe}}^{\gamma}=0.7^{[9]} \\
& T_{\mathrm{Néel}, \mathrm{Fe}: \mathrm{Va}}^{\gamma}=T_{\mathrm{Néel,Fe}: \mathrm{C}}^{\gamma}=T_{\mathrm{Néel,Fe}}^{\gamma}=67^{[9]}
\end{aligned}
$$

$\gamma^{\prime}$, model $\mathrm{Fe}_{4}(\mathrm{C}, \mathrm{N}, \mathrm{Va})$

$$
\begin{aligned}
& { }^{\circ} G_{\mathrm{Fe}: \mathrm{C}}^{\gamma^{\prime}}-4^{\circ} G_{\mathrm{Fe}}^{\alpha, \text { non-mag }}-{ }^{\circ} G_{\mathrm{C}}^{\mathrm{gra}}=20,000 \\
& { }^{\circ} G_{\mathrm{Fe}: \mathrm{N}}^{\gamma^{\prime}}-4^{\circ} G_{\mathrm{Fe}}^{\alpha, \text { non-mag }}-\frac{1}{2}{ }^{\circ} G_{\mathrm{N}_{2}}^{\text {gas }}=-37,744+72.786 T \\
& { }^{\circ} G_{\mathrm{Fe}: \mathrm{Va}}^{\gamma^{\prime}}-4^{\circ} G_{\mathrm{Fe}}^{\alpha, \text { non-mag }}=12,066+3.691 T
\end{aligned}
$$

$\varepsilon$, model $\mathrm{Fe}(\mathrm{C}, \mathrm{N}, \mathrm{Va})_{1 / 2}$

$$
\begin{aligned}
& { }^{\circ} G_{\mathrm{Fe}: \mathrm{Va}}^{\varepsilon}={ }^{\circ} G_{\mathrm{Fe}}^{\varepsilon} \\
& { }^{\circ} G_{\mathrm{Fe}: \mathrm{C}}^{\varepsilon}-{ }^{\circ} G_{\mathrm{Fe}}^{\gamma}-\frac{1}{2}{ }^{\circ} G_{\mathrm{C}}^{\mathrm{gra}}=52,905-11.9075 T^{[96]}
\end{aligned}
$$$$
{ }^{\circ} G_{\mathrm{Fe}: \mathrm{N}}^{\varepsilon}-{ }^{\circ} G_{\mathrm{Fe}}^{\alpha}-\frac{1}{4}{ }^{\circ} G_{\mathrm{N}_{2}}^{\mathrm{gas}}=-13,863+40.2123 T^{[22]}
$$

${ }^{0} L_{\mathrm{Fe}: \mathrm{C}, \mathrm{Va}}^{\varepsilon}=-53059$

${ }^{1} L_{\mathrm{Fe}: \mathrm{C}, \mathrm{Va}}^{\varepsilon}=-38,756$

${ }^{0} L_{\mathrm{Fe}: \mathrm{N}, \mathrm{Va}}^{\varepsilon}=8186-18.127 T$

${ }^{1} L_{\mathrm{Fe}: \mathrm{N}, \mathrm{Va}}^{\varepsilon}=-24,378+24.959 T$

${ }^{0} L_{\mathrm{Fe}: \mathrm{C}, \mathrm{N}}^{\varepsilon}=-20,772-32.504 T$

${ }^{1} L_{\mathrm{Fe}: \mathrm{C}, \mathrm{N}}^{\varepsilon}=-28,839$

$\theta$, model $\mathrm{Fe}_{3}(\mathrm{C}, \mathrm{Va})$

$$
\begin{aligned}
& { }^{\circ} G_{\mathrm{Fe}: \mathrm{C}}^{\theta, \text { non-mag }}-3 H_{\mathrm{Fe}}^{\mathrm{SER}}-H_{\mathrm{C}}^{\mathrm{SER}}=-8983+658.38 T-113.578 T \ln T-3.059 \times 10^{-3} T^{2}+6.105 \times 10^{5} T^{-1[7]} \\
& { }^{\circ} G_{\mathrm{Fe}: \mathrm{Va}}^{\theta, \text { non }}-3^{\circ} G_{\mathrm{Fe}}^{\alpha, \text { non-mag }}=44,782-11.59 T^{[7]} \\
& \beta_{\mathrm{Fe}: \mathrm{C}}^{\theta}=\beta_{\mathrm{Fe}: \mathrm{Va}}^{\theta}=1.51^{[7]} \\
& T_{\mathrm{Curie}, \mathrm{Fe}: \mathrm{C}}^{\theta}=T_{\mathrm{Curie}, \mathrm{Fe}: \mathrm{Va}}^{\theta}=485^{[10]}
\end{aligned}
$$

$T$ in $\mathrm{K}$, values of Gibbs energy and interaction parameters in $\mathrm{J} \mathrm{mol}^{-1}$.

also below) and, therefore, disagrees with the experimental phase-boundary data at low temperatures (cf. Figure 2(a)).

The calculated phase boundaries of the $\gamma$ single-phase field agree well with the few available experimental data, see Figure 2(b). Experimental data on the phase boundaries $\gamma / \gamma+\gamma^{\prime}$ and $\gamma / \gamma+\varepsilon$ is somewhat contradictory: recent investigations obtained by EPMA measurements on nitrided specimens ${ }^{[15]}$ showed $\mathrm{N}$ contents of up to 1 at. pct less than given in older works. ${ }^{[67,70,74,83]}$ For the phase boundary $\gamma / \gamma+\gamma^{\prime}$, the predictions by the thermodynamic description from the present work lie between these values. For the phase boundary $\gamma / \gamma+\varepsilon$, the data from Reference 15 is described better than the data from References 67, 70, 74, and 83. Overall, a good representation of all data employed in the optimisation 
Table III. Comparison of Temperatures and Compositions of Phases Participating in the Invariant Reactions

\begin{tabular}{|c|c|c|c|c|c|c|}
\hline Reaction & Reference & $T\left[\mathrm{~K}\left({ }^{\circ} \mathrm{C}\right)\right]$ & $x_{\mathrm{N}}^{\alpha}($ at. pct) & $x_{\mathrm{N}}^{\gamma}$ (at. pct) & $x_{\mathrm{N}}^{\gamma^{\prime}}($ at. pct) & $x_{\mathrm{N}}^{\varepsilon}$ (at. pct) \\
\hline \multirow[t]{5}{*}{$\varepsilon \rightleftharpoons \gamma^{\prime}$} & present work (pred) & $964(691)$ & & & 19.6 & 19.6 \\
\hline & [12] (exp) & $953(680)$ & & & 19.5 & 19.5 \\
\hline & [15] (exp) & $938-948(665-675)$ & & & $\mathrm{N} / \mathrm{A}$ & $\mathrm{N} / \mathrm{A}$ \\
\hline & [22] (pred) & $971(698)$ & & & 19.4 & 19.4 \\
\hline & [24] (pred) & $955(682)$ & & & 19.6 & 19.6 \\
\hline \multirow[t]{5}{*}{$\varepsilon \rightleftharpoons \gamma+\gamma^{\prime}$} & present work (pred) & $923(650)$ & & 9.7 & 19.1 & 16.3 \\
\hline & {$[12](\exp )$} & $923(650)$ & & 10.3 & 19.3 & 15.9 \\
\hline & [15] (exp) & $923-925(650-652)$ & & $\mathrm{N} / \mathrm{A}$ & $\mathrm{N} / \mathrm{A}$ & $\mathrm{N} / \mathrm{A}$ \\
\hline & [22] (pred) & $923(650)$ & & 9.7 & 19.1 & 16.1 \\
\hline & [24] (pred) & $923(650)$ & & 10.3 & 19.6 & 15.9 \\
\hline \multirow[t]{5}{*}{$\gamma \rightleftharpoons \alpha+\gamma^{\prime}$} & present work (pred) & $865(592)$ & 0.39 & 9.0 & 19.2 & \\
\hline & [12] (exp) & $865(592)$ & 0.40 & 8.8 & 19.3 & \\
\hline & [13] (exp) & $866(593)$ & 0.44 & $\mathrm{~N} / \mathrm{A}$ & $\mathrm{N} / \mathrm{A}$ & \\
\hline & [22] (pred) & $863(590)$ & 0.39 & 9.0 & 19.3 & \\
\hline & [24] (pred) & 867 (594) & 0.40 & 8.9 & 19.6 & \\
\hline
\end{tabular}

exp, Experimentally determined; pred, predicted by a thermodynamic description.

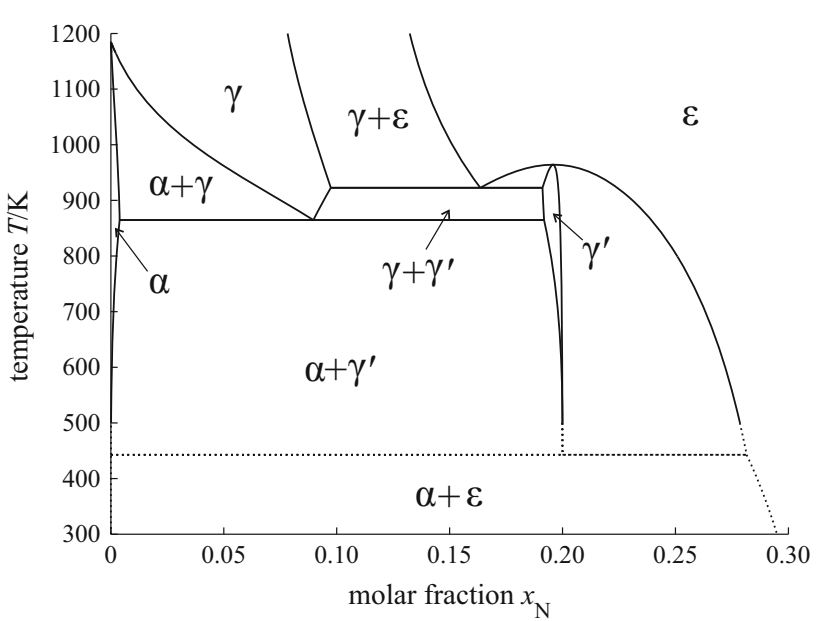

Fig. 1-The Fe-N phase diagram as calculated using the thermodynamic description from the present work, suppressing formation of the $\mathrm{N}_{2}$ gas phase. At a temperature below $443 \mathrm{~K}\left(170{ }^{\circ} \mathrm{C}\right)$, an $\alpha+\varepsilon$ equilibrium is predicted, see the dotted lines (see discussion in Section $\mathrm{V}-\mathrm{B}$ )

is given, also accounting for the error margins of the usually applied EPMA method to determine these phase-boundary compositions.

The $\gamma^{\prime} / \gamma^{\prime}+\varepsilon$ phase boundary agrees well with the experimental data from Reference 87 , whereas the $\mathrm{N}$ content at the phase boundary $\alpha+\gamma^{\prime} / \gamma^{\prime}$ is lower than indicated by most of the experimental data and by the phase boundary as calculated using the thermodynamic description from Reference 22, but still agrees within less than 0.1 at. pct (see Figure 2(c)). Better agreement could be achieved by introducing a more advanced model considering $\mathrm{N}$ disorder, see Section $\mathrm{V}-\mathrm{C}$.

The thermodynamic description from the present work reproduces the phase boundary $\gamma^{\prime}+\varepsilon / \varepsilon$ significantly better than the previous descriptions ${ }^{[22,24]}$ (see Figure 2(d)). The data point from Reference 66 and semi-quantitative investigations in Reference 97 suggest that the phase boundary $\gamma^{\prime}+\varepsilon / \varepsilon$ might extend to lower
$\mathrm{N}$ contents in the low- $T$ range. In this low- $T$ range, the agreement of the experimental data with the phase boundary from Reference 98, based on a thermodynamic description considering ordering of $\mathrm{N}$ on its sublattice, is better, which is also shown in Figure 2(d). The thermodynamic description of Reference 98, however, gives multiple expressions for the phase boundary in order to cover the whole temperature range (see the overlap of the two curves in Figure 2(d)). Moreover, in the high- $T$ range, the agreement with the experimental data is poor and there is a maximum in the proposed phase boundary. This is thermodynamically only possible if the congruent transition $\varepsilon \rightleftharpoons \gamma^{\prime}$ occurs at $\mathrm{N}$ contents as high as 21.2 at. pct, which is impossible according to the model from the present work (maximum $\mathrm{N}$ content of $\gamma^{\prime}$ is 20 at. pct) and also incompatible with the prediction according to the model for $\gamma^{\prime}$ from Reference 98.

A "potential phase diagram" using the activity of $\mathrm{N}$ (reference state $\mathrm{N}_{2}$ gas at $1 \times 10^{5} \mathrm{~Pa}$ and at the considered temperature) as a variable is shown in Figure 3(a), allowing comparison of the phase boundaries as calculated using the thermodynamic description from the present work with the respective phase boundaries as calculated using the datasets from References 22 and 24, the phase boundary $\gamma^{\prime} / \varepsilon$ as calculated using the expressions given in Reference 98, and the phase boundaries as indicated by the experimental data. $^{[13,25,68,69,71,76,77,79,82,85]}$ The same diagram using as a variable the often applied nitriding potential

$$
r_{\mathrm{N}}=\frac{p_{\mathrm{NH}_{3}}}{p_{\mathrm{H}_{2}}^{3 / 2}},
$$

a (technical process) parameter used for gaseous nitriding, which is a measure for the activity of $\mathrm{N}$, but multiplied with ${ }^{\circ} p^{1 / 2}$ (where ${ }^{\circ} p=1 \times 10^{5} \mathrm{~Pa}$ is the pressure of the reference state, to obtain a dimensionless variable $\left.^{[1]}\right)$, is given in Figure $3(\mathrm{~b})$. For the phase boundary $\alpha / \gamma^{\prime}$, the thermodynamic dataset of the present work describes the experimental data equally 


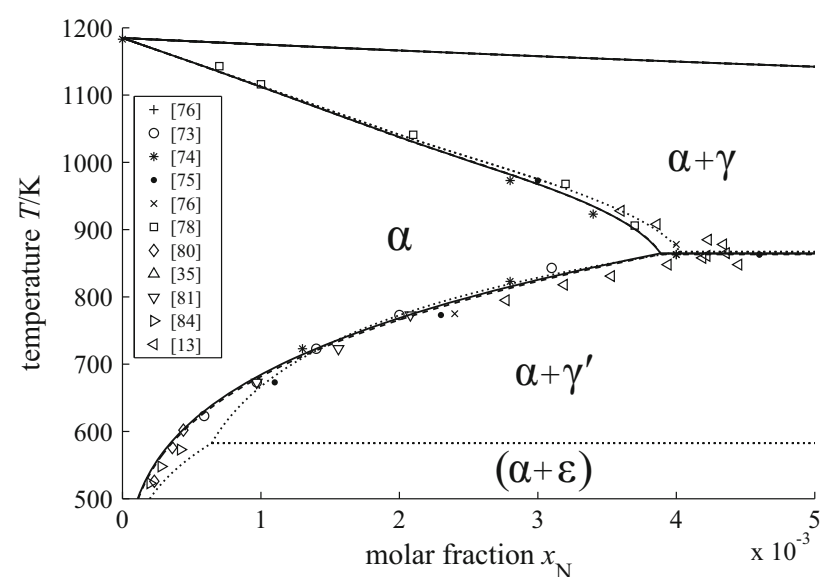

(a)

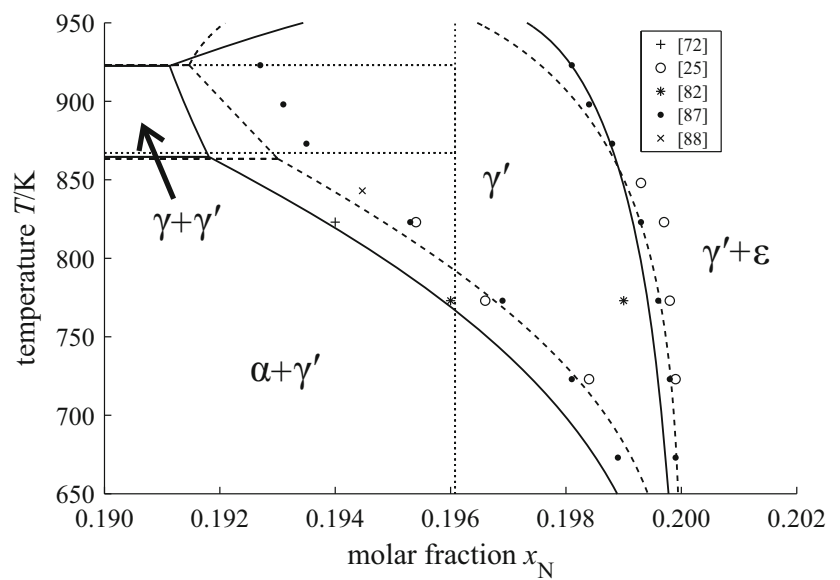

(c)

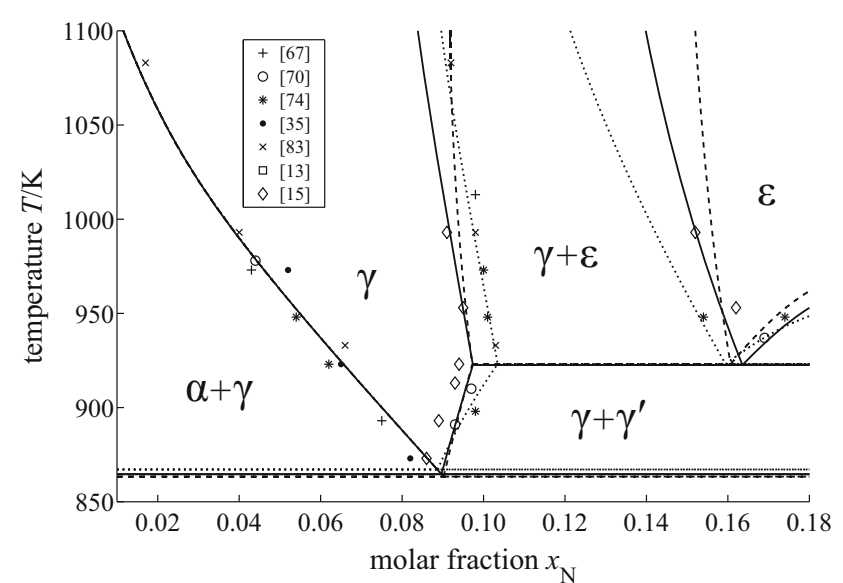

(b)

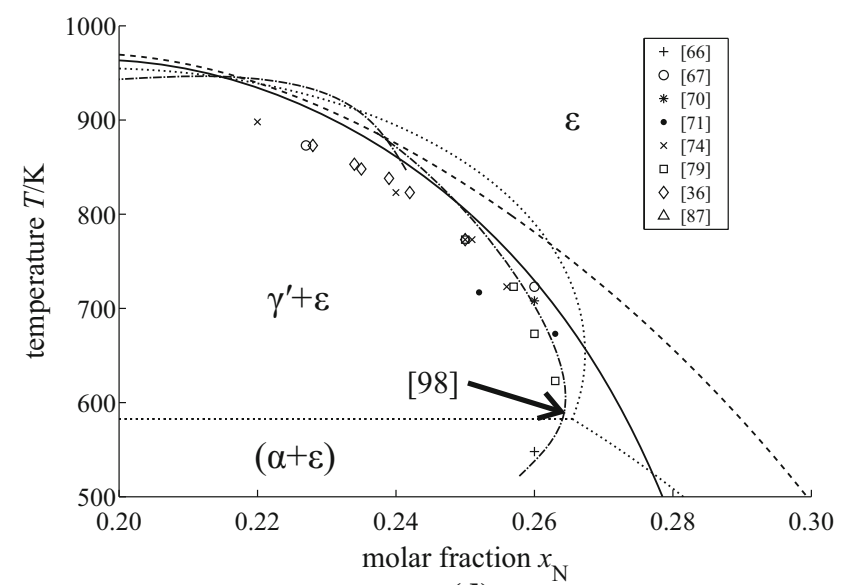

(d)

Fig. 2-Magnified sections of the Fe-N phase diagram as calculated using the thermodynamic description from the present work (solid lines) in comparison to (i) the phase diagrams as calculated using the descriptions from Refs. [22] (dashed lines) and [24] (dotted lines) and (ii) various experimental data. An $\alpha+\varepsilon$ equilibrium is predicted using the description of Ref. [24] in the shown temperature range. (a) Low N-content range with experimental data from Refs. [13,35, 67, 73-76, 78, 80,81] and [84]. (b) Equilibria involving the $\gamma$ phase compared with experimental data from Refs. [13, 15, 35, 67, 70, 74] and [83]. (c) The homogeneity range of $\gamma^{\prime}$ compared with experimental data from Refs. [25, 72, 82, 87] and [88]. Note that the thermodynamic description of Ref. [24] describes $\gamma^{\prime}$ as a stoichiometric compound with the formula $\mathrm{Fe}_{4.1} \mathrm{~N}$. $(d)$ The $\gamma^{\prime}+$ $\varepsilon / \varepsilon$ phase boundary compared with experimental data from Refs. [36, 66, 67, 70, 71, 74, 79] and [87]. Also, the phase boundary redrawn from Fig. 4 in Ref. [98] (variant for low N content) is shown.

as well as the dataset published in Reference 22. For the $\gamma$ range, the thermodynamic descriptions from the present work and from References 22 and 24 reproduce the experimental data well. However, the phase boundary $\gamma^{\prime} / \varepsilon$ as calculated using the thermodynamic dataset of the present work agrees significantly better with the experimental data than the phase boundaries resulting from the previous descriptions of References 22 and 24 . The phase boundary $\gamma^{\prime} / \varepsilon$ is even better described with the expressions given in Reference 98. However, in that work direct least-squares fitting of the phase boundary was performed, yielding several expressions for different temperature ranges. The thermodynamics of both the binary and ternary $\gamma^{\prime}$ and $\varepsilon$ phases are discussed in a comparative manner in Sections $\mathrm{V}-\mathrm{C}$ and $\mathrm{V}-\mathrm{D}$, respectively.

Including the thermodynamic description of the liquid $\mathrm{Fe}-\mathrm{N}$ phase from Reference 21 peritectic melting of $\varepsilon$ is predicted in the binary $\mathrm{Fe}-\mathrm{N}$ system at $1654 \mathrm{~K}$ $\left(1381{ }^{\circ} \mathrm{C}\right)$. A similar prediction is obtained from the thermodynamic descriptions of the $\mathrm{Fe}-\mathrm{N}$ system of References 21 and 22. The thermodynamic descriptions from References 20 and 24, however, predict a congruent transition $\gamma \rightleftharpoons \varepsilon$. Since there is no corresponding experimental data available, no conclusion can be drawn which variant is correct. Nevertheless, the shape of the $\gamma$ phase field as predicted by References 20 and 24 seems unrealistic. Thus, the thermodynamic description involving peritectic melting is the preferred one, at least until more experimental data is available.

At low temperatures, an $\alpha+\varepsilon$ equilibrium is predicted by the presently obtained thermodynamic description, which disappears upon heating at $443 \mathrm{~K}\left(170{ }^{\circ} \mathrm{C}\right.$, see the dotted lines in Figure 1). The same feature at low temperature is predicted using the thermodynamic descriptions from References 20, 22 and 24. The appearance of an $\alpha+\varepsilon$ equilibrium at low temperatures is not necessarily a modeling artifact: experimental investigations ${ }^{[99-101]}$ 


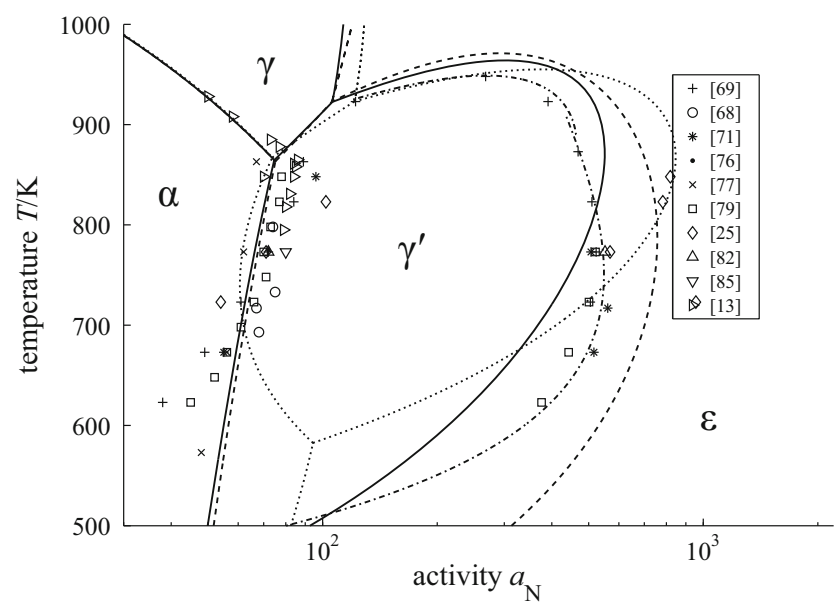

(a)

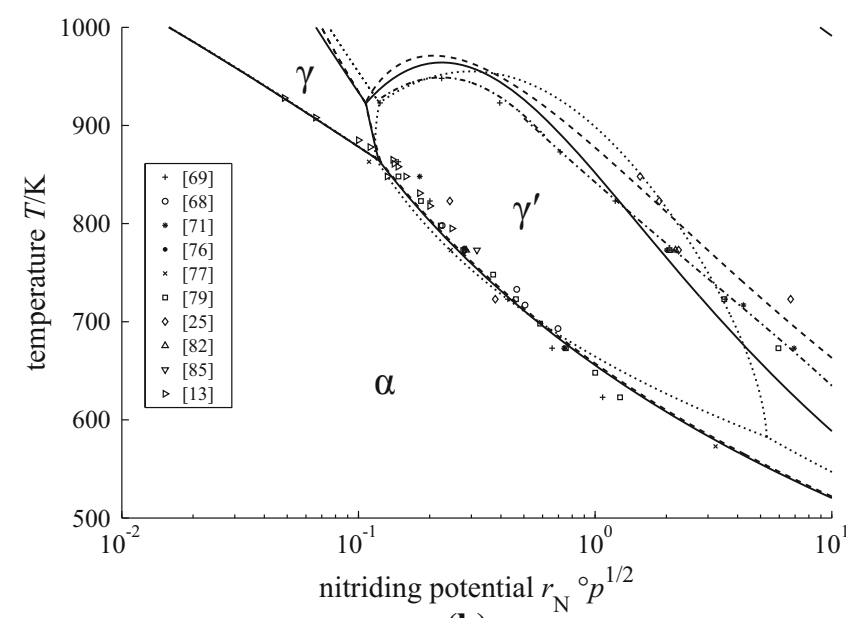

(b)

$$
\text { present work }
$$

Fig. 3-Potential phase diagrams as calculated using the thermodynamic description from the present work (solid lines), and as calculated using the descriptions from Refs. [22] (dashed lines) and [24] (dotted lines). For comparison, the phase boundary $\gamma^{\prime} / \varepsilon$ as given by Eqs. [14b/c] in Ref. [98] (dash-dot lines) and experimental data for the phase boundaries from Refs. [13, 25, 68, 69, 71, 76, 77, 79, 82] and [85] are also shown. (a) Using the activity of $\mathrm{N}$ as a variable (reference state $\mathrm{N}_{2}$ gas at $1 \times 10^{5} \mathrm{~Pa}$ and the respective temperature). (b) Using the nitriding potential $r_{\mathrm{N}}=p_{\mathrm{NH}_{3}} / p_{\mathrm{H}_{2}}^{3 / 2}$ (multiplied with ${ }^{\circ} p^{1 / 2}$ to obtain a dimensionless quantity) as a variable, which is a measure for the activity of $\mathrm{N}^{[1]}$

suggested that $\varepsilon$ was in equilibrium with $\alpha$ at low temperatures [approximately $\left.\leq 550 \mathrm{~K}\left(280{ }^{\circ} \mathrm{C}\right)\right]$. Another work $^{[97]}$ excluded the possibility of the $\alpha+\varepsilon$ equilibrium in the binary $\mathrm{Fe}-\mathrm{N}$ system at low temperatures and discussed the possible formation of the cubic $\alpha^{\prime \prime}-\mathrm{Fe}_{16} \mathrm{~N}_{2}$ nitride as an equilibrium phase, which was not included in the present assessment. At least at $623 \mathrm{~K}\left(350{ }^{\circ} \mathrm{C}\right)$ (and at higher temperatures), precipitation of $\gamma^{\prime}$ from $\varepsilon$ was still observed. ${ }^{[102]}$ However, due to the very slow kinetics at those low temperatures it is difficult to reach a genuine equilibrium state and this prohibits to draw a final conclusion. Finally, as a fine point, recent ab initio calculations pertaining to $0 \mathrm{~K}\left(-273{ }^{\circ} \mathrm{C}\right)^{[103,104]}$ indicate that a mechanical mixture of pure $\alpha$-Fe and $\varepsilon-\mathrm{Fe}_{3} \mathrm{~N}$ with a gross $\mathrm{N}$ content of 20 at. pct has a lower enthalpy than pure $\gamma^{\prime}-\mathrm{Fe}_{4} \mathrm{~N}$, supporting the occurrence of an $\alpha+\varepsilon$ equilibrium at low temperature. It is noted that this point was not addressed specifically in these works. ${ }^{[103,104]}$

\section{B. The Ternary Fe- $\mathrm{N}-\mathrm{C}$ System}

A Scheil reaction scheme $e^{[105-107]}$ illustrating the sequence of invariant reactions as resulting from the present thermodynamic description of the Fe-N-C system is shown in Figure 4. The temperatures of the invariant reactions in the $\mathrm{Fe}-\mathrm{N}-\mathrm{C}$ system as calculated using the thermodynamic description of the present work can be compared in Table IV with the corresponding experimental data and the predictions as obtained using the thermodynamic descriptions from References 22 and 24, which are the two thermodynamic descriptions giving the best agreement with experimentally determined invariant temperatures ${ }^{[15,53]}$ according to the detailed discussion in Reference 53. Both Figure 4 and Table IV use the designations for the invariant reactions introduced in Reference 53. The possibilities for the sequence of invariant reactions in the system $\mathrm{Fe}-\mathrm{N}-\mathrm{C}$ below $853 \mathrm{~K}\left(580{ }^{\circ} \mathrm{C}\right)$ have been discussed in detail in Reference 53, offering two possibilities realized by the previous various thermodynamic descriptions for the Fe-N-C system. ${ }^{[20,22,24,55-57]}$ In the first case, upon cooling, the $\alpha+\varepsilon$ equilibrium is replaced by the $\gamma^{\prime}+\theta$ equilibrium via a single transition reaction $\mathrm{U}_{2}, \alpha+\varepsilon \rightleftharpoons \gamma^{\prime}+\theta$. In the second case, upon cooling, the $\gamma^{\prime}+\theta$ equilibrium first appears via the pseudo-binary eutectoid reaction $\mathrm{e}_{4}, \varepsilon \rightleftharpoons \gamma^{\prime}+\theta$, dividing the $\varepsilon$ single phase field into two separate $\varepsilon$ single phase fields. Subsequently, the second $\varepsilon$ single phase field vanishes via the ternary eutectoid reaction $\mathrm{E}_{2}, \varepsilon \rightleftharpoons$ $\alpha+\gamma^{\prime}+\theta$. The thermodynamic description of the present work reproduces the first sequence of invariant reactions (see Figure 4).

The temperature of the transitional reaction $U_{2}$ as calculated using the dataset from the present work $[839 \mathrm{~K}$ $\left.\left(566{ }^{\circ} \mathrm{C}\right)\right]$ is only slightly below the value of the temperature for this reaction as determined experimentally $\left[842 \pm 2 \mathrm{~K}\left(569 \pm 2{ }^{\circ} \mathrm{C}\right)\right] .{ }^{[53]}$ The here predicted temperatures of the $\mathrm{U}_{1}$ and $\mathrm{E}_{1}$ invariant reactions are within the boundaries determined experimentally for these reactions in Reference 15. The previous thermodynamic descriptions for the system Fe-N-C $\mathrm{C}^{[20,22,24,54-57]}$ only describe a part of the invariant temperatures correctly and give significantly deviating values for other ones (see the discussion in Reference 53 and the examples in Table IV). In contrast, the new thermodynamic description predicts correctly the values of all invariant temperatures, as recently determined experimentally.

Isothermal sections of the Fe-N-C phase diagram as calculated using the thermodynamic dataset derived in the present work at the (technologically relevant) temperatures of $853 \mathrm{~K}$ and $893 \mathrm{~K}\left(580{ }^{\circ} \mathrm{C}\right.$ and $\left.620^{\circ} \mathrm{C}\right)$ are shown in Figure 5 together with the phase boundaries as proposed in Reference 15 on the basis of EPMA investigations on nitrocarburizing Fe specimens. These experimental data have been used in the optimization process. 
Table IV. Comparison of the Temperatures of the Invariant Reactions in the Ternary Fe-N-C System, Using the Designations for the Invariant Reactions Introduced in Ref. [53]

\begin{tabular}{|c|c|c|c|c|}
\hline Reaction & Experiment & This Work & Ref. [22] & Ref. [24] \\
\hline $\mathrm{U}_{1}, \gamma+\theta \rightleftharpoons \alpha+\varepsilon$ & 868 to $873(595 \text { to } 600)^{[15]}$ & $873(600)$ & $867(594)$ & $952(679)$ \\
\hline $\mathrm{E}_{1}, \gamma \rightleftharpoons \alpha+\gamma^{\prime}+\varepsilon$ & 853 to $863(580 \text { to } 590)^{[15]}$ & $857(584)$ & $859(586)$ & $857(584)$ \\
\hline $\mathrm{U}_{2}, \alpha+\varepsilon \rightleftharpoons \gamma^{\prime}+\theta$ & $842 \pm 2(569 \pm 2)^{[53]}$ & $839(566)$ & $783(510)$ & - \\
\hline $\mathrm{E}_{2}, \varepsilon \rightleftharpoons \gamma^{\prime}+\theta$ & 840 to $844(567 \text { to } 571)^{[53]}$ & - & - & $833(560)$ \\
\hline $\mathrm{e}_{4}, \varepsilon \rightleftharpoons \alpha+\gamma^{\prime}+\theta$ & 840 to $844(567 \text { to } 571)^{[53]}$ & - & - & $825(552)$ \\
\hline
\end{tabular}

All values in $\mathrm{K}\left({ }^{\circ} \mathrm{C}\right)$; as predicted by the present thermodynamic description and the descriptions from Refs. [22] and [24] and as experimentally determined in the cited literature.

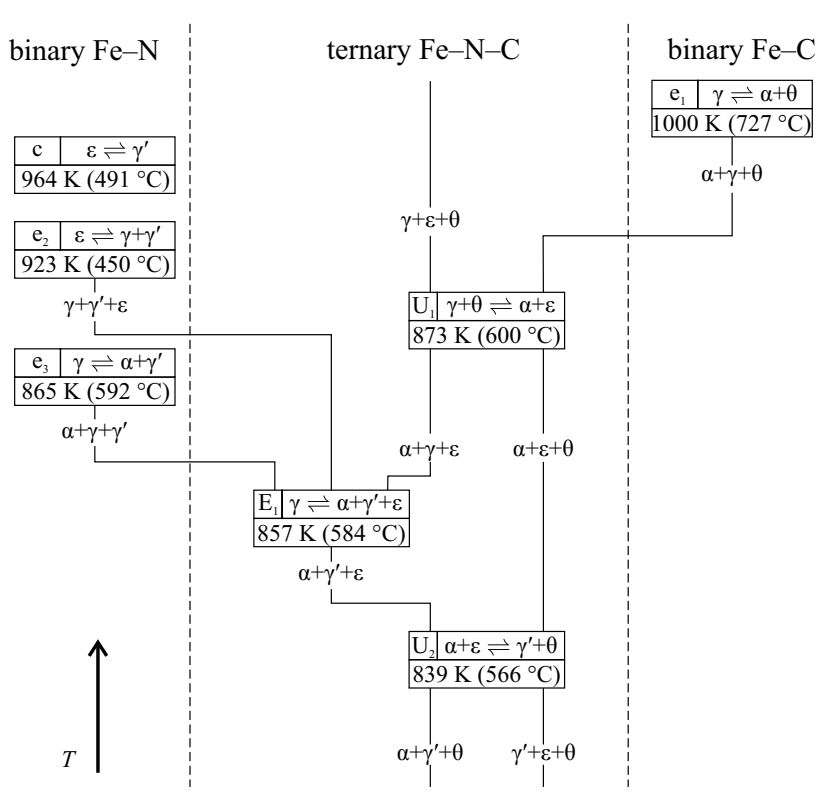

Fig. 4 - Scheil reaction scheme representing the sequence of invariant reactions predicted by the thermodynamic description from the present work, using the designations for the invariant reactions introduced in Ref. [53].

It was not possible to obtain an even better fit of the phase boundaries without allowing the formation of a large miscibility gap in the $\varepsilon$ phase. The agreement with the phase boundaries from Reference 15 at $853 \mathrm{~K}\left(580{ }^{\circ} \mathrm{C}\right)$ is significantly better than as obtained by the predictions from References 22 and 55 and comparable to the phase boundaries resulting from the prediction from Reference 24 as follows from Figure $8 d$ in Reference 15. At the same temperature, according to the descriptions from References 56 and 57 , the $\alpha+\varepsilon$ equilibrium is non-existent or just disappearing. Therefore, the phase boundaries resulting from these descriptions cannot be compared to experimental data or to the phase boundaries resulting from the description from the present work. Further experimental data points have been given in Figure 5(a): (i) the single data point from Reference 41 for the phase boundary $\alpha+\varepsilon / \varepsilon$ shows higher $\mathrm{N}$ and lower $\mathrm{C}$ contents than predicted here; (ii) the data points for the same phase boundary from Reference 46 (for 120 and 240 minutes), however, agree well with the calculations from the present work; (iii) recent experimental data measured at $853 \mathrm{~K}$ $\left(580{ }^{\circ} \mathrm{C}\right.$ ) for either the $\alpha+\varepsilon / \varepsilon$ or the $\alpha+\varepsilon+\theta / \varepsilon$ equilibrium $^{[51]}$ also agree well with the predictions from the present work.

At $893 \mathrm{~K}\left(620^{\circ} \mathrm{C}\right)$, the agreement with the experimental data is also good, especially for the $\gamma$ single phase field, with the deviations between the data from Reference 15 and the calculated phase boundaries being close to the accuracy of EPMA. There is a clear deviation at $893 \mathrm{~K}\left(620^{\circ} \mathrm{C}\right)$ for the phase boundary $\gamma^{\prime}+\varepsilon / \varepsilon$. However, the phase boundary given there is an estimation which is compatible with EPMA data presented in the same work but not based on a thermodynamic model. In principle, the phase boundary as predicted by the thermodynamic description from the present work is compatible with the EPMA data from Reference 15, see their Figure 8(b). Thermodynamic calculations at the same temperature using the description from Reference 22 showed significantly higher $\mathrm{N}$ contents an lower $\mathrm{C}$ contents in $\varepsilon$ for the equilibria with $\gamma$ and especially $\theta$ than determined in Reference 15 and predicted by the thermodynamic description from the present work.

Both at $853 \mathrm{~K}$ and $893 \mathrm{~K}\left(580{ }^{\circ} \mathrm{C}\right.$ and $\left.620^{\circ} \mathrm{C}\right)$, the phase boundaries of the $\gamma^{\prime}$ phase show excellent agreement with those shown in Reference 15. The ternary $\gamma^{\prime}$ single phase field given there is, however, not based on quantitative experimental data, but has only estimative character. The $\gamma^{\prime}$ single phase field resulting from the model from the present work agrees well with the EPMA data mentioned in Section III-B.

The priority in the present work was to obtain a reasonable representation of the phase boundaries of $\gamma$ at $893 \mathrm{~K}\left(620^{\circ} \mathrm{C}\right)$ and to describe correctly the invariant temperatures. On this basis, the parameter ${ }^{0} L_{\mathrm{Fe}: \mathrm{C}, \mathrm{N}}^{\gamma}$ was optimized. In order to obtain a better description of $\gamma$ in the range of higher temperatures, a temperature dependence of ${ }^{0} L_{\mathrm{Fe}: \mathrm{C}, \mathrm{N}}^{\gamma}$ could be introduced as soon as more experimental data is available. Even though systematically too low, the here determined prediction for the $\mathrm{N}$ solubility in carbon containing $\gamma$ is already good; see the comparison of experimental data ${ }^{[90]}$ and the values predicted by the thermodynamic description from the present work in Table V.

\section{The Appropriateness of a Model for the $\gamma^{\prime}$ Phase}

In the present work, a different approach for modeling the thermodynamics of $\gamma^{\prime}$ than in Reference 22 has been used. Instead of setting ${ }^{\circ} G_{\mathrm{Fe}: \mathrm{Va}}^{\gamma^{\prime}}$ equal to the Gibbs energy of $\gamma-\mathrm{Fe}$ and introducing interaction parameters, 


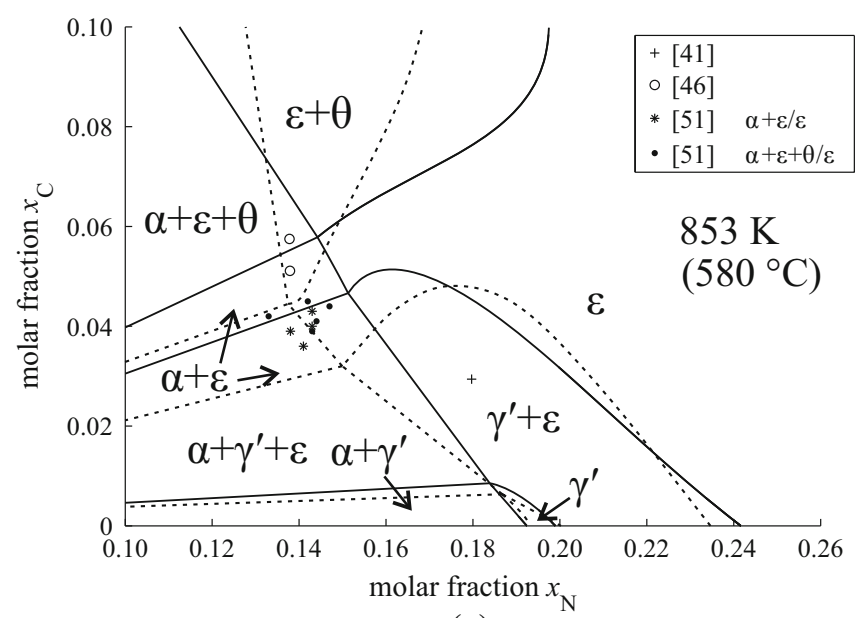

(a)

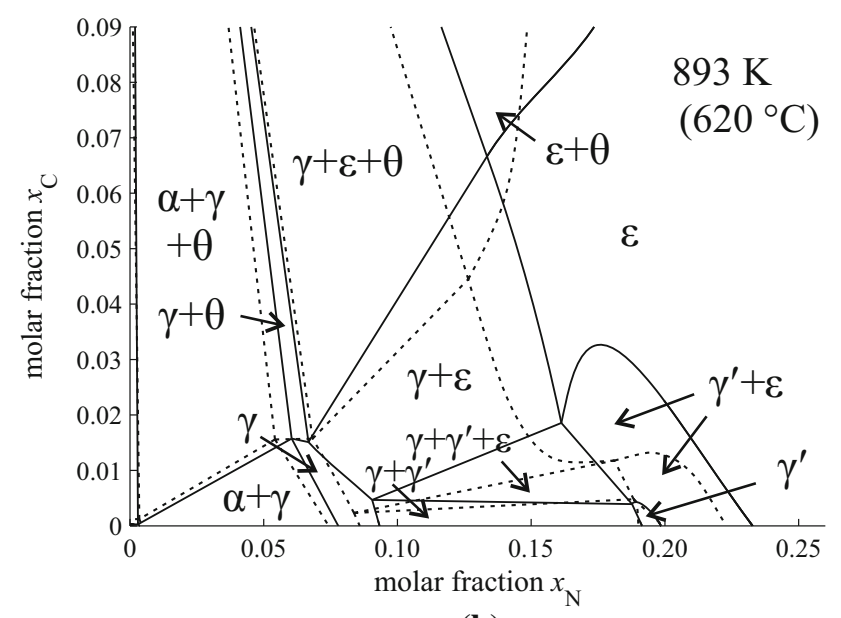

(b)

Fig. 5-Isothermal sections of the Fe-N-C phase diagram calculated using the thermodynamic description from the present work (solid lines) compared with phase boundaries proposed in Ref. [15] (dashed lines). (a) At $853 \mathrm{~K}\left(580^{\circ} \mathrm{C}\right)$, also including separate data from Refs. [41, 46] and [51]. (b) At $893 \mathrm{~K}\left(620^{\circ} \mathrm{C}\right)$.

Table V. The Solubility of $\mathbf{N}$ in $\mathbf{C}$-containing $\gamma$ in Equilibrium with $\mathrm{N}_{2}$ Gas at $1 \times 10^{5} \mathrm{~Pa}$ as Experimentally Determined in Ref. $[90]$ and as Predicted by the Model from the Present Work

\begin{tabular}{|c|c|c|c|}
\hline $\begin{array}{l}T \\
{\left[\mathrm{~K}\left({ }^{\circ} \mathrm{C}\right)\right]}\end{array}$ & $\begin{array}{c}w_{\mathrm{C}} \\
(\mathrm{wt} \mathrm{pct})^{\mathrm{a}}\end{array}$ & $\begin{array}{c}w_{\mathrm{N}} \times 10^{2} \\
(\mathrm{wt} \text { pct }) \\
(\exp , \text { Ref. }[90])\end{array}$ & $\begin{array}{c}w_{\mathrm{N}} \times 10^{2} \\
(\mathrm{wt} \text { pct }) \\
(\text { calc, this work) }\end{array}$ \\
\hline $1323(1050)$ & 0.57 & 2.28 & 2.04 \\
\hline \multirow[t]{2}{*}{1373 (1100) } & 0.44 & 2.25 & 2.03 \\
\hline & 0.75 & 2.12 & 1.82 \\
\hline \multirow[t]{4}{*}{$1423(1150)$} & 0.43 & 2.18 & 1.95 \\
\hline & 0.50 & 2.18 & 1.90 \\
\hline & 0.76 & 2.00 & 1.75 \\
\hline & 0.76 & 1.94 & 1.75 \\
\hline \multirow[t]{3}{*}{$1473(1200)$} & 0.46 & 2.08 & 1.86 \\
\hline & 0.50 & 2.07 & 1.84 \\
\hline & 0.78 & 1.88 & 1.68 \\
\hline
\end{tabular}

Compositions expressed in mass fractions $w_{\mathrm{N}}$ and $w_{\mathrm{C}}$.

aTheoretically, for the experiments considered in Ref. [90], the activity of $\mathrm{C}$ is zero at the surface of the specimen. However, as there is no decarburizing medium in the gas phase, $\mathrm{C}$ remains in the substrate.

${ }^{\circ} G_{\mathrm{Fe}: \mathrm{Va}}^{\gamma^{\prime}}$ has been used as a model parameter. Its value should, therefore, not be interpreted as the Gibbs energy of a hypothetical compound. The physical meaning of the value of ${ }^{\circ} G_{\mathrm{Fe}: \mathrm{Va}}^{\gamma^{\prime}}-4^{\circ} G_{\mathrm{Fe}}^{\alpha}$ can be understood as the Gibbs energy of N-vacancy formation according to the formal reaction $(1-x) \mathrm{Fe}_{4} \mathrm{~N}+4 x \alpha-\mathrm{Fe} \rightleftharpoons \mathrm{Fe}_{4} \mathrm{~N}_{1-x}$, as similarly described in References 6 and 7. As mentioned in Section IV, the parameter ${ }^{\circ} G_{\mathrm{Fe}: \mathrm{C}}^{\gamma^{\prime}}$ was adjusted in a way that the solubility of $\mathrm{C}$ in $\gamma^{\prime}$ agrees well with the experimental equilibrium values. Therefore, a physical interpretation is even more difficult. Ab initio calculations performed in Reference 108 indicated a positive enthalpy of formation of $\gamma^{\prime}-\mathrm{Fe}_{4} \mathrm{C}$ as it is the case in the present work.

Experimentally obtained data for the relationship of the activity of $\mathrm{N}$ and the $\mathrm{N}$ content of $\gamma^{\prime},{ }^{[25]}$ for the binary
Fe-N system, were discussed in detail in Reference 26. In that work modeling was performed using three different approaches and the results were compared with the thermodynamic description from Reference 22. The "Langmuir-type approach" in Reference 26 is identical to the model applied in the present work. The other two models ("Wagner-Schottky (WS) approach" and "Gorsky-Bragg-Williams (GBW) approach") allow for (dis)order of N. In Figure 1 in Reference 26, a function characterizing the deviation of the thermodynamic data from the expected values according to a Langmuir-type model (yielding a constant value for this function), is plotted showing the good fit of the WS and GBW models to the experimental data from Reference 25 . Thus, it was concluded $^{[26]}$ that a model allowing for disorder is needed in order to give a meaningful description of the thermodynamics of the $\gamma^{\prime}$ phase, with the "WS approach" and the "GBW approach" giving equally meaningful descriptions.

Using the expressions for the Gibbs energy of $\gamma^{\prime}$ in Reference 109 it can be shown that also the WS and GBW models, allowing for disorder of $\mathrm{N}$, can be expressed in the compound energy formalism ${ }^{[59]}$ using a sublattice model indicated by the formula unit $\mathrm{Fe}_{4}(\mathrm{~N}, \mathrm{Va})(\mathrm{N}, \mathrm{Va})_{3}$, i.e., as compared to the sublattice model applied in the present work with the formula unit $\mathrm{Fe}_{4}(\mathrm{~N}, \mathrm{Va})$, with a second interstitial sublattice, and ideal (WS) or regular (GBW) interactions. Following the conclusion from Reference 26, we then tried to use a model equivalent to the "WS approach" from Reference 26 in the binary Fe-N system. The optimization of the model parameters, however, gave unreasonable results with $e . g$., $\gamma^{\prime}$ replacing the $\gamma$ phase or no disorder in $\gamma^{\prime}$ at all. This is caused by a lack of any direct experimental data quantifying disorder in $\gamma^{\prime}$. Other approaches to the thermodynamics of the $\gamma^{\prime}$ phase adopt the cluster variation method, ${ }^{[27-29,110]}$ but the experimental data do not allow to prefer one or the other model:

If realistic errors for the $\mathrm{N}$-content determination in Reference 25 are assumed (approximately $5 \mathrm{pct}$ ), the resulting deviations from the experimental results of the 


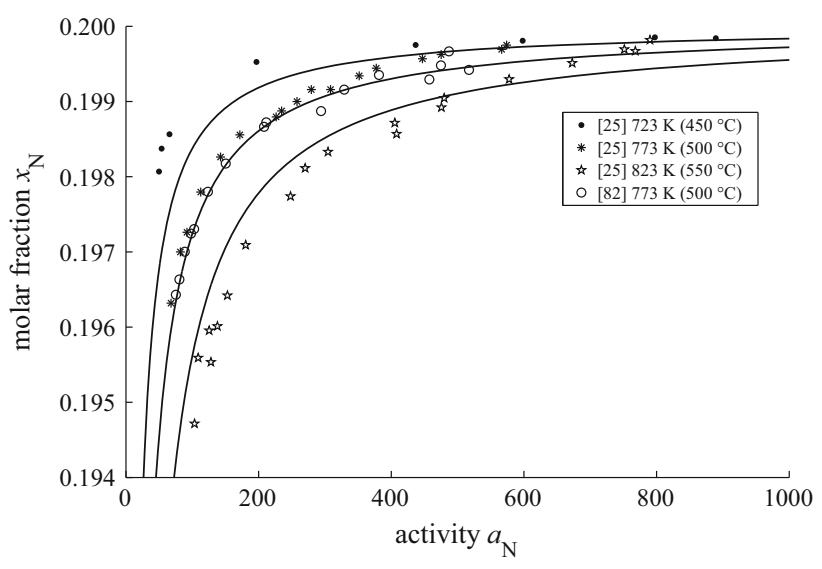

Fig. 6 - Comparison of the predicted relationship of $\mathrm{N}$ activity and $\mathrm{N}$ content for binary $\gamma^{\prime}$ (solid lines) and the experimental data from Refs. [25] and [82].

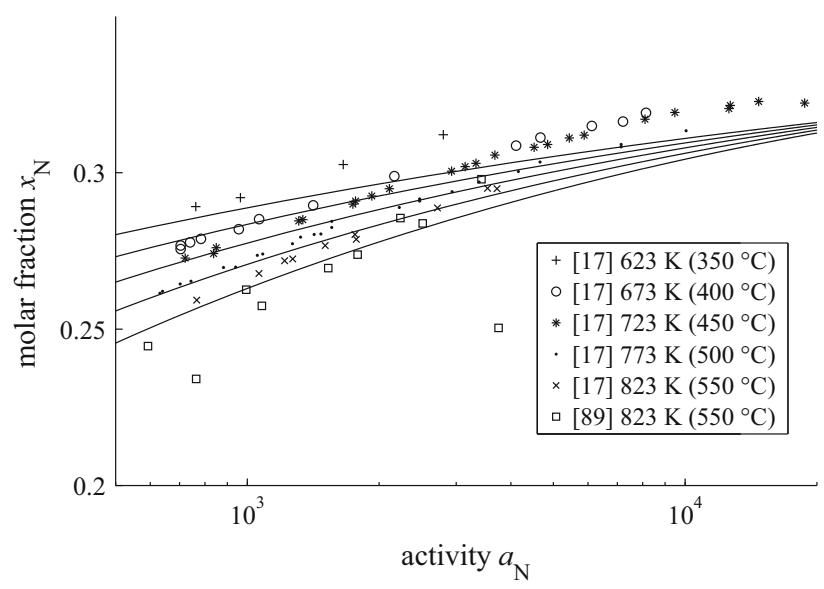

Fig. 7-Comparison of the relationship of $\mathrm{N}$ activity and $\mathrm{N}$ content in binary $\varepsilon$ resulting from the thermodynamic description from the present work (lines), with $T$ increasing from $623 \mathrm{~K}$ to $823 \mathrm{~K}\left(350{ }^{\circ} \mathrm{C}\right.$ to $550{ }^{\circ} \mathrm{C}$ ) in steps of $50 \mathrm{~K}$ from top to bottom, and experimental data from Refs. [17] and [89].

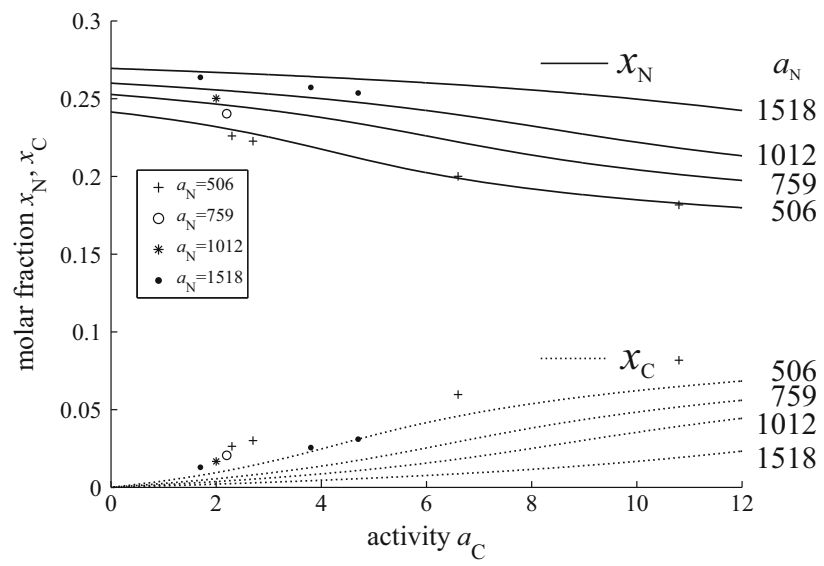

Fig. 8- The relationships of $\mathrm{N}$ and $\mathrm{C}$ activities and $\mathrm{N}$ content (solid lines) and $\mathrm{C}$ content (dotted lines) of $\varepsilon$ at $843 \mathrm{~K}\left(570{ }^{\circ} \mathrm{C}\right)$ as predicted by the thermodynamic description from the present work and as determined experimentally in Ref. [112] (individual data points). model used in the present work can be ascribed to this experimental uncertainty. Therefore, and also because the solubility of $\mathrm{C}$ in $\gamma^{\prime}$ is considered, it was decided to adopt the two-sublattice model in the present work, giving a reasonable agreement of the predicted activity curves and the data from References 25 and 82 (see Figure 6).

\section{The Thermodynamics of the $\&$ Phase}

The values of the Gibbs energy of the end-members of $\varepsilon,{ }^{\circ} G_{\mathrm{Fe}: \mathrm{C}}^{\varepsilon}$ and ${ }^{\circ} G_{\mathrm{Fe}: \mathrm{N}}^{\varepsilon}$ have been taken from previous descriptions. ${ }^{[22,96]}$ The enthalpies of formation following from these Gibbs-energy functions are compatible with recent $a b$ initio data from Reference 111, predicting negative values close to the one following from the applied Gibbs-energy function for various ordering states of nitrides with the formula $\mathrm{Fe}_{2} \mathrm{~N}$. The values for the corresponding carbides with the formula $\mathrm{Fe}_{2} \mathrm{C}$ from Reference 111 are positive as it is the case for the Gibbs-energy function applied in the present work, whereas they are considerably smaller.

The relationship of the activity of $\mathrm{N}$ and the $\mathrm{N}$ content in $\varepsilon$ for the binary Fe-N system as obtained from the present thermodynamic description is shown in Figure 7. The prediction agrees well with the (rather inaccurate) experimental data (errors in the range of 5 to 10 at. pct) from Reference 89, as follows from Figure 7. Considering the more accurate data from Reference 17, shown in Figure 7 as well, good agreement occurs in the region of low $\mathrm{N}$ content and low $\mathrm{N}$ activity; at higher $\mathrm{N}$ activities lower $\mathrm{N}$ contents are predicted than experimentally observed. It was not possible to reproduce these data better without losing the good agreement with the twoand three-phase equilibrium data in which $\varepsilon$ participates. In the present work, the thermodynamics of the $\varepsilon$ phase have been described focusing on correct description of the available solid-solid equilibrium data. The description of the activity of $\mathrm{N}$ in $\varepsilon$ on the basis of the gas-solid equilibrium data from References 17 and 89 could be better described by using models more explicitly considering the state of order in $\varepsilon$ than that in the present case.

Several approaches have been presented in the literature to describe the thermodynamic behavior of $\varepsilon$ in the range of high $\mathrm{N}$ content, i.e., close to the maximum $\mathrm{N}$ content of $x_{\mathrm{N}}=1 / 3$. Descriptions on the basis of a long-range order, GBW model of $\varepsilon$ have been presented in References 14, 30, and 31, similar to the approach mentioned above for $\gamma^{\prime},{ }^{[26]}$ and descriptions on the basis of the cluster variation method have been presented in References 27 and 32. Finally, ordering in $\varepsilon$ and also the equilibrium with orthorhombic $\zeta-\mathrm{Fe}_{2} \mathrm{~N}$ (not considered in the present work), which can formally be described as ordered $\varepsilon$, have been investigated recently by first-principles calculations. ${ }^{[33]}$ Recognizing the large homogeneity ranges of $\mathrm{N}$ and $\mathrm{C}$ in $\varepsilon$ and the necessary extension of the binary model into the ternary Fe-N-C system, it is reasonable to apply a sub-regular solution model for $\varepsilon$ indicated by the formula unit $\mathrm{Fe}(\mathrm{C}, \mathrm{N}, \mathrm{Va})_{1 / 2}$, and therefore, handle all non-ideal (e.g., ordering) effects by introducing interaction parameters instead of applying a physically more meaningful, but disproportionally 
complex long-range order model. This approach has been adopted in the present work, thereby enabling successful description of the equilibria in both the binary $\mathrm{Fe}-\mathrm{N}$ system and especially the ternary Fe-N-C system.

In the present work, the function for ${ }^{\circ} G_{\mathrm{Fe}: \mathrm{N}}^{\varepsilon}$ has been taken from Reference 22. Comparison of the Gibbs energy of $\varepsilon-\mathrm{Fe}_{2} \mathrm{~N}$ as predicted by this function and by the thermodynamic description for $\varepsilon$ from Reference 24 , i.e., setting $y_{\mathrm{N}}^{\varepsilon}=1 / 2$ for the $1: 1$ model applied there, shows that the corresponding Gibbs-energy values are virtually identical over a large temperature range.

The relationships of the $\mathrm{N}$ and $\mathrm{C}$ activities and the $\mathrm{N}$ and $\mathrm{C}$ contents of $\varepsilon$ at $843 \mathrm{~K}\left(570{ }^{\circ} \mathrm{C}\right)$ have been plotted in Figure 8 together with the experimental data from Reference 112. The agreement is very good for $\mathrm{N}$. Compared to the experimental data, the predicted $\mathrm{C}$ contents are too low for high $\mathrm{N}$ activities; for low $\mathrm{N}$ activities, the predicted values are closer to the experimentally determined ones. Similar experimental investigations have been performed in Reference 113, but are not included here recognizing the application of technical steels, i.e., a high impurity content, for the specimens used in Reference 113.

A general trend visible in Figure 8 is the obvious mutual influence of $\mathrm{N}$ and $\mathrm{C}$ : an increase in the $\mathrm{C}$ activity leads to a decrease of the $\mathrm{N}$ content and vice versa. This can be discussed as follows:

Simultaneous interstitial diffusion of $\mathrm{N}$ and $\mathrm{C}$ in $\varepsilon$ is governed by the thermodynamic factor

$$
\vartheta_{i j}=\frac{y_{i}}{R T} \frac{\partial \mu_{i}}{\partial y_{j}}
$$

with the chemical potential of component $i(=\mathrm{N}, \mathrm{C}), \mu_{i}$, being the proportional constant between the intrinsic diffusion coefficients and the corresponding self-diffusion coefficients. ${ }^{[51,58,114]}$ It has been found that at both $823 \mathrm{~K}$ and $853 \mathrm{~K}\left(550{ }^{\circ} \mathrm{C}\right.$ and $\left.580{ }^{\circ} \mathrm{C}\right)$ the off-diagonal components of $\vartheta_{i j}$ are positive. ${ }^{[51,58]}$ This information has been used as a constraint during the optimization: the thermodynamic description from the present work results in positive values of the off-diagonal components of the thermodynamic factor over a large composition range of $\varepsilon$. Only at low $\mathrm{N}$ and $\mathrm{C}$ contents, not covered by the experimentally observable homogeneity ranges of $\varepsilon$, negative values of those off-diagonal components of $\vartheta_{i j}$ occur.

The present thermodynamic description predicts that a small miscibility gap occurs in $\varepsilon$ below approximately $855 \mathrm{~K}\left(582{ }^{\circ} \mathrm{C}\right)$ close to the line connecting $\mathrm{Fe}_{2} \mathrm{~N}$ and $\mathrm{Fe}_{2} \mathrm{C}$. No experimental data exist to (in)validate this result.

\section{CONCLUSIONS}

1. New thermodynamic descriptions for the Fe-N system and the Fe-N-C system have been developed by focusing on the equilibria involving the $\gamma^{\prime}$ and $\varepsilon$ phases.

2. A simple ideal-solution model for the $\gamma^{\prime}$ phase has been used to describe successfully its homogeneity range; the past models either use considerably more model parameters to yield a similar description of the experimental data or unrealistically model $\gamma^{\prime}$ as a stoichiometric phase.

3. In the binary Fe-N system, the new thermodynamic description reproduces the experimental data better than previously published thermodynamic descriptions, especially the $\gamma^{\prime}+\varepsilon$ equilibrium. The agreement with the experimental data for both the $\mathrm{N}$ content of $\varepsilon$ and the activity of $\mathrm{N}$ at the phase boundary $\gamma^{\prime} / \varepsilon$ has been improved significantly.

4. The thermodynamic descriptions available in literature cannot reproduce recently obtained experimental data. Therefore, a thermodynamic description of the ternary Fe-N-C system correctly describing especially the recently experimentally observed temperatures of the invariant reactions has been developed. The new thermodynamic description for the ternary Fe-N-C system also well reproduces the recently obtained experimental phase boundaries in the system as well as the (positive) off-diagonal components of the thermodynamic factor (pertaining to diffusion in $\varepsilon$; as determined from experiments).

\section{ACKNOWLEDGMENTS}

Open access funding provided by Max Planck Institute for Intelligent Systems (formerly Max Planck Institute for Metals Research).

\section{OPEN ACCESS}

This article is distributed under the terms of the Creative Commons Attribution 4.0 International License (http://creativecommons.org/licenses/by/4.0/), which permits unrestricted use, distribution, and reproduction in any medium, provided you give appropriate credit to the original author(s) and the source, provide a link to the Creative Commons license, and indicate if changes were made.

\section{ELECTRONIC SUPPLEMENTARY MATERIAL}

The online version of this article (doi:10.1007/ s11661-016-3731-0) contains supplementary material, which is available to authorized users.

\section{REFERENCES}

1. Thermochemical Surface Engineering of Steels, 3rd ed., E.J. Mittemeijer, and M.A.J. Somers, eds., Thermochemical Surface Engineering of Steels, Woodhead Publishing, Cambridge, 2015. 
2. D.H. Jack and K.H. Jack: Mater. Sci. Eng., 1973, vol. 11, pp. 1-27.

3. E.J. Mittemeijer: ASM Handbook, Vol. 4A, Steel Heat Treating Fundamentals and Processes, Chapter Fundamentals of Nitriding and Nitrocarburizing, ASM International, New York, 2013, pp. 619-46.

4. E.J. Mittemeijer: Fundamentals of Materials Science, Springer, Heidelberg, 2011

5. H. Okamoto: J. Phase Equilib., 1992, vol. 13, pp. 543-65.

6. A. Leineweber, S.L. Shang, and Z.K. Liu: Acta Mater., 2015, vol. 86 , pp. 374-84.

7. H. Göhring, A. Leineweber, and E.J. Mittemeijer: $C A L P H A D$, 2016, vol. 52, pp. 38-46.

8. J. Ågren: Metall. Trans. A, 1979, vol. 10A, pp. 1847-52.

9. P. Gustafson: Scand. J. Metall., 1985, vol. 14, pp. 259-67.

10. B. Hallstedt, D. Djurovic, J. von Appen, R. Dronskowski, A. Dick, F. Körmann, T. Hickel, and J. Neugebauer: CALPHAD, 2010, vol. 34, pp. 129-33.

11. R. Naraghi, M. Selleby, and J. Ågren: CALPHAD, 2014, vol. 46, pp. $148-58$.

12. H.A. Wriedt, N.A. Gokcen, and R.H. Nafziger: J. Phase Equilib., 1987, vol. 8, pp. 355-77.

13. J. Stein, R.E. Schacherl, M.S. Jung, S. Meka, B. Rheingans, and E.J. Mittemeijer: Int. J. Mater. Res. (formerly Z. Metallkd.), 2013, vol. 104, pp. 1053-65.

14. M.A.J. Somers, B.J. Kooi, L. Maldzinski, E.J. Mittemeijer, A.A. van der Horst, A.M. van der Kraan, and N.M. van der Pers: Acta Mater., 1997, vol. 45, pp. 2013-25.

15. T. Woehrle, H. Cinaroglu, A. Leineweber, and E.J. Mittemeijer: Int. J. Mater. Res. (formerly Z. Metallkd.), 2016, vol. 107, pp. 192-202.

16. M. Hillert and M. Jarl: Metall. Trans. A, 1975, vol. 6A, pp. 553-59.

17. L. Maldzinski, Z. Przylecki, and J. Kunze: Steel Res., 1986, vol. 57, pp. 645-49.

18. J. Kunze: Steel Res., 1986, vol. 57, pp. 361-67.

19. K. Frisk: CALPHAD, 1987, vol. 11, pp. 127-34.

20. J. Kunze: Nitrogen and Carbon in Iron and Steel. Thermodynamics, Akademie-Verlag, Berlin, 1990

21. K. Frisk: CALPHAD, 1991, vol. 15, pp. 79-106.

22. H. Du: J. Phase Equilib., 1993, vol. 14, pp. 682-93.

23. A.F. Guillermet and H. Du: Z. Metallkd., 1994, vol. 85, pp. 154-63.

24. J. Kunze: Härt.-Tech. Mitt., 1996, vol. 51, pp. 348-55.

25. H.J. Grabke: Ber. Bunsen-Ges. Phys. Chem, 1969, vol. 73, pp. 596-601.

26. B.J. Kooi, M.A.J. Somers, and E.J. Mittemeijer: Metall. Mater. Trans. A, 1996, vol. 27A, pp. 1055-61.

27. M.I. Pekelharing, A.J. Böttger, and E.J. Mittemeijer: Philos. Mag., 2003, vol. 83, pp. 1775-96.

28. S. Shang and A.J. Böttger: Acta Mater., 2005, vol. 53, pp. 255-64.

29. A.J. Böttger, D.E. Nanu, and A. Marashdeh: Comput. Mater. Sci., 2014, vol. 95 , pp. 8-12.

30. B.J. Kooi, M.A.J. Somers, and E.J. Mittemeijer: Metall. Mater. Trans. A, 1994, vol. 25A, pp. 2797-814.

31. M.I. Pekelharing, A. Böttger, M.A.J. Somers, M.P. Steenvoorden, A.M. van der Kraan, and E.J. Mittemeijer: Mater. Sci. Forum, 1999, vols. 318-320, pp. 115-20.

32. S. Shang and A.J. Böttger: Acta Mater., 2003, vol. 51, pp. 3597-3606.

33. M.B. Bakkedal: Ph.D. Thesis, Technical University of Denmark, 2015.

34. K.H. Jack: Proc. R. Soc. London, Ser. A, 1948, vol. 185, pp. 41-55.

35. E. Scheil, W. Mayr, and J. Müller: Arch. Eisenhüttenwes., 1962, vol. 33 , pp. 385-92.

36. F.K. Naumann and G. Langenscheid: Arch. Eisenhüttenwes., 1965, vol. 36, pp. 677-82.

37. D. Gerardin, H. Michel, J.P. Morniroli, and M. Gantois: Mem. Sci. Rev. Metall., 1977, vol. 74, pp. 457-67.

38. D. Gerardin, H. Michel, and M. Gantois: Scr. Metall., 1977, vol. 11, pp. 557-61.

39. J. Matauschek and H. Trenkler: Härt.-Tech. Mitt., 1977, vol. 32, pp. 177-81.
40. E.J. Mittemeijer, W.T.M. Straver, P.F. Colijn, P.J. van der Schaaf, and J.A. van der Hoeven: Scr. Metall., 1980, vol. 14, pp. 1189-92.

41. A. Wells and T. Bell: Heat Treat. Met., 1983, vol. 10, pp. 39-44.

42. H.C.F. Rozendaal, F. Colijn, and E.J. Mittemeijer: Surf. Eng., 1985, vol. 1, pp. 30-42.

43. A. Wells: J. Mater. Sci., 1985, vol. 20, pp. 2439-45.

44. A. Wells: Thin Solid Films, 1985, vol. 128, pp. L33-36.

45. M.A.J. Somers and E.J. Mittemeijer: Surf. Eng., 1987, vol. 3, pp. 123-37.

46. M.A.J. Somers, P.F. Colijn, W.G. Sloof, and E.J. Mittemeijer: $Z$. Metallkd., 1990, vol. 81, pp. 33-43.

47. H. Du, M.A.J. Somers, and J. Ågren: Metall. Mater. Trans. A, 2000, vol. 31A, pp. 195-211.

48. M. Nikolussi, A. Leineweber, E. Bischoff, and E.J. Mittemeijer: Int. J. Mater. Res. (formerly Z. Metallkd.), 2007, vol. 98, pp. $1086-1092$

49. T. Wöhrle, A. Leineweber, and E.J. Mittemeijer: J. Heat Treatm. Mat., 2010, vol. 65, pp. 243-48.

50. T. Woehrle, A. Leineweber, and E.J. Mittemeijer: Metall. Mater. Trans. A, 2012, vol. 43A, pp. 2401-13.

51. H. Göhring, A. Leineweber, and E.J. Mittemeijer: Metall. Mater. Trans. A, 2015, vol. 46A, pp. 3612-26.

52. H. Göhring, S. Kante, A. Leineweber, and E.J. Mittemeijer: Int. J. Mater. Res. (formerly Z. Metallkd.), 2016, vol. 107, pp. 203-216.

53. H. Göhring, A. Leineweber, and E.J. Mittemeijer: Metall. Mater. Trans. A, 2016, vol. 47A, pp. 4411-24.

54. S. Hertzman: Metall. Trans. A, 1987, vol. 18A, pp. 1753-66.

55. J. Slycke, L. Sproge, and J. Ågren: Scand. J. Metall., 1988, vol. 17, pp. 122-26.

56. H. Du and M. Hillert: Z. Metallkd., 1991, vol. 82, pp. 310-16.

57. P. Franke and H.J. Seifert, eds.: Landolt-Börnstein - Group IV Physical Chemistry, Volume 19C1-Thermodynamic Properties of Inorganic Materials Compiled by SGTE. Ternary Steel Systems: Phase Diagrams and Phase Transition Data, Springer, Berlin, 2012

58. T. Woehrle, A. Leineweber, and E.J. Mittemeijer: Metall. Mater. Trans. A, 2013, vol. 44A, pp. 2548-62.

59. M. Hillert: J. Alloys Compd., 2001, vol. 320, pp. 161-76.

60. H. Lukas, S.G. Fries, and B. Sundman: Computational Thermodynamics - The Calphad Method, Cambridge University Press, Cambridge, 2007.

61. M. Hillert and L.-I. Staffansson: Acta Chem. Scand., 1970, vol. 24, pp. 3618-26.

62. O. Redlich and A.T. Kister: Ind. Eng. Chem., 1948, vol. 40, pp. 345-48.

63. M. Hillert: Phase Equilibria, Phase Diagrams and Phase Transformations, Cambridge University Press, Cambridge, 2007.

64. G. Inden: in Project Meeting CALPHAD V, W. Pitsch, ed., 1976 pp. III.4-1-13.

65. M. Hillert and M. Jarl: CALPHAD, 1978, vol. 2, pp. 227-38.

66. E. Lehrer: Z. Techn. Phys., 1929, vol. 10, pp. 177-85.

67. O. Eisenhut and E. Kaupp: Z. Elektrochem., 1930, vol. 36, pp. 392-404.

68. P.H. Emmett, S.B. Hendricks, and S. Brunauer: J. Am. Chem. Soc., 1930, vol. 52, pp. 1456-64.

69. E. Lehrer: Z. Elektrochem., 1930, vol. 36, pp. 383-92.

70. E. Lehrer: Z. Elektrochem., 1930, vol. 36, pp. 460-73.

71. S. Brunauer, M.E. Jefferson, P.H. Emmett, and S.B. Hendricks: J. Am. Chem. Soc., 1931, vol. 53, pp. 1778-86.

72. C. Guillaud and H. Creveaux: Compt. Rend. Acad. Sci. Paris, 1946, vol. 222, pp. 1170-72.

73. L.J. Dijkstra: Trans. AIME, 1949, vol. 185, pp. 252-60.

74. L.B. Paranjpe, M. Cohen, M.B. Bever, and C.F. Floe: Trans. AIME, 1950, vol. 188, pp. 261-67.

75. A. Burdese: Metall. Ital., 1955, vol. 47, pp. 357-61.

76. N.S. Corney and E.T. Turkdogan: J. Iron Steel Inst., 1955, vol. 180 , pp. $344-48$

77. J.D. Fast and M.B. Verrijp: J. Iron Steel Inst., 1955, vol. 180, pp. $337-43$

78. W. Pitsch and E. Houdremont: Arch. Eisenhüttenwes., 1956, vol. 27, pp. 281-84.

79. A. Burdese: Ann. Chim. (Rome, Italy), 1959, vol. 49, pp. $1873-1884$. 
80. M. Nacken and J. Rahmann: Arch. Eisenhüttenwes., 1962, vol. 33, pp. 131-40.

81. H.A. Wriedt: J. Phase Equilib., 1987, vol. 8, pp. 355-77.

82. H.A. Wriedt: Trans. TMS-AIME, 1969, vol. 245, pp. 43-46.

83. D. Atkinson and C. Bodsworth: J. Iron Steel Inst., 1970, vol. 208, pp. 587-93.

84. K. Abiko and Y. Imai: Trans. Jpn. Inst. Met, 1977, vol. 18, pp. 113-24.

85. H.H. Podgurski and F.N. Davis: Acta Metall., 1981, vol. 29, pp. $1-9$.

86. M.W. Chase Jr.: NIST-JANAF Thermochemical Tables, Fourth Edition, J. Phys. Chem. Ref. Data, Monograph 9, 1998.

87. Data shown in J. Kunze: Nitrogen and Carbon in Iron and Steel. Thermodynamics. Akademie-Verlag, Berlin, 1990, cited as Z. Przylecki, L. Maldzinski, private communication.

88. M.A.J. Somers and E.J. Mittemeijer: Metall. Trans. A, 1990, vol. 21A, pp. 189-204

89. W.D. Jentzsch and S. Böhmer: Krist. Techn., 1977, vol. 12, pp. $1275-83$.

90. H. Schenck, M.G. Frohberg, and F. Reinders: Stahl Eisen, 1963, vol. 83, pp. 93-99.

91. A. Kagawa and T. Okamoto: Trans. Jpn. Inst. Met., 1981, vol. 22 , pp. $137-43$.

92. T. Gressmann, M. Nikolussi, A. Leineweber, and E.J. Mittemeijer: Scr. Mater., 2006, vol. 55, pp. 723-26.

93. M. Nikolussi, A. Leineweber, and E.J. Mittemeijer: Philos. Mag., 2010, vol. 90, pp. 1105-22.

94. H.S. Kitaguchi, S. Lozano-Perez, and M.P. Moody: Ultramicroscopy, 2014, vol. 147, pp. 51-60.

95. A.T. Dinsdale: CALPHAD, 1991, vol. 15, pp. 317-425.

96. J.-O. Andersson: CALPHAD, 1988, vol. 12, pp. 9-23.

97. S. Malinov, A.J. Böttger, E.J. Mittemeijer, M.I. Pekelharing, and M.A.J. Somers: Metall. Mater. Trans. A, 2001, vol. 32A, pp. $59-73$.
98. B.J. Kooi, M.A.J. Somers, and E.J. Mittemeijer: Metall. Mater. Trans. A, 1996, vol. 27A, pp. 1063-71.

99. D.K. Inia, M.H. Pröpper, W.M. Arnoldbik, A.M. Vredenberg, and D.O. Boerma: Appl. Phys. Lett., 1997, vol. 70, pp. 1245-47.

100. E.H. Du Marchie van Voorthuysen, B. Feddes, N.G. Chechenin, D.K. Inia, A.M. Vredenberg, and D.O. Boerma: Phys. Stat. Sol. A, 2000, vol. 177, pp. 127-33.

101. E.H. Du Marchie, D.O. van Voorthuysen, Boerma, and N.C. Chechenin: Metall. Mater. Trans. A, 2002, vol. 33A, 2593-98.

102. A. Leineweber, J. Aufrecht, and E. J. Mittemeijer: Int. J. Mater. Res. (formerly Z. Metallkd.), 2006, vol. 97, pp. 753-59.

103. Y. Imai, M. Sohma, and T. Suemasu: J. Alloys Compd., 2014, vol. 611, pp. $440-45$.

104. J.-S. Chen, C. Yu, and H. Lu: J. Alloys Compd., 2015, vol. 625, pp. 224-30

105. E. Scheil: Arch. Eisenhüttenwes., 1936, vol. 9, pp. 571-73.

106. H.L. Lukas, E.-T. Henig, and G. Petzow: Z. Metallkd., 1986, vol. 77, pp. 360-67.

107. B. Predel, M. Hoch, and M. Pool: Phase Diagrams and Heterogeneous Equilibria, Springer, Berlin, Heidelberg, 2004.

108. C.M. Fang, M.A. van Huis, B.J. Thijsse, and H.W. Zandbergen: Phys. Rev. B, 2012, vol. 85, pp. 054116-1-054116-7.

109. B.J. Kooi: Iron-Nitrogen Phases: Ph.D. thesis, TU Delft, 1995.

110. M.I. Pekelharing, A.J. Böttger, M.A.J. Somers, and E.J. Mittemeijer: Metall. Mater. Trans. A, 1999, vol. 30A, pp. 1945-53.

111. C.M. Fang, M.A. van Huis, J. Jansen, and H.W. Zandbergen: Phys. Rev. B, 2011, vol. 84, pp. 094102-1-094102-10.

112. S. Pietzsch, S. Böhmer, and H.-J. Spies: in Proceedings of the Second International Conference on Carburizing and Nitriding with Atmospheres, 1995, pp. 295-300.

113. S. Hoja, H. Klümper-Westkamp, F. Hoffmann, and H.-W. Zoch: J. Heat Treatm. Mat., 2010, vol. 65, pp. 22-29.

114. J.S. Kirkaldy and D.J. Young: Diffusion in the Condensed State, The Institute of Metals, London, 1987. 